\title{
ORGANIZACOTES $\mathbb{E}$

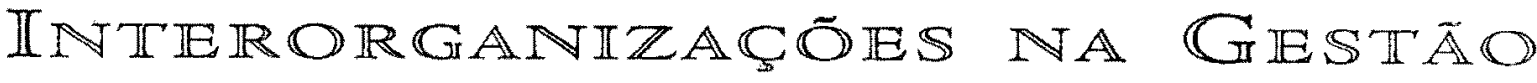 DO IDESENVOIVINIENTO SOCIOA $\mathbb{I} \mathbb{E} \mathbb{R} \mathbb{I} \mathbb{I} \mathbb{R} \mathbb{A} \mathbb{L}^{*}$

\author{
Tânia Fischer**
} \\ Vanessa Paternostro Melo***
}

RESUMO

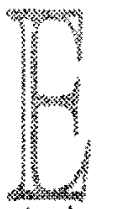

ste estudo reflete sobre interorganizações orientadas ao desenvolvimento sócioterritorial, revisitando o conceito de estrutura referenciada a organizações de textura complexa. Parcerias, consórcios, pactos, dentre outros formatos identificáveis em diversas escalas territoriais, apresentam estrutura hibridizada reticular, agenciadas por organizações públicas e privadas, em diversas formas de associação. Credita-se às organizações associativas um protagonismo decisivo na ativação de redes e redes de redes, formatos interorganizacionais aos quais se atribui o poder de gerir o desenvolvimento territorial, ora mais orientados à competição, ora mais orientados às ações solidárias.

$\mathrm{Na}$ intenção de melhor compreender a gênese e a textura das interorganizações voltadas ao desenvolvimento territorial, foram estudadas 180 organizações associativas em Salvador, Bahia, realizando uma pesquisa de tipo survey transeccional.

Conclui-se com a caracterização destas organizações e com a discussão de seu papel nas conexões interorganizacionais integrantes de estratégias de desenvolvimento sócio-territorial, destacando-se ambigüidades, contradições e possibilidades.

\section{$A \mathbb{A B S T R A C T}$}

$$
\text { (3) }
$$

his paper contemplates territorial development-oriented interorganizations and reexamines structural concepts referring to complex-textured organizations. Partnerships, consortiums, pacts among other identifiable formats in several territorial levels, present an intricate hybrid structure developed by private or public organizations in many forms of association. It is credited to such organizations an important role in the creation of networks and networks within networks, interorganizational formats to which is attributed the power of managing territorial development, now competition-oriented or more disposed to joint actions.

With the purpose of better understanding the genesis and texture of territorial development-oriented interorganizations, 180 of such organizations were studied in Salvador, Bahia through a trans-sectional survey.

This study concludes with the characterization of such organizations and discussion of their role in interorganizational associations incorporating socio-territorial development strategies specially ambiguities, fontradictions and possibilities.

\footnotetext{
* Participaram deste trabalho na qualidade de bolsista de iniciação cientifica os alunos Renata Rossi (CNPq), Sávio Costa (CNPQ), Marlos André (PIBIC/UFBA), Ademário de lesus (PIBIC/UFBA) e Renata Andrade (CNPQ) e Jair Soares como consultor estatistico.

** Profa NPGA/EAUFBA

*** Pesquisadora do Núcleo de Estudos sobre Poder e Organizações Locais. Bolsista FAPESB
} 
DESENVOLVIMENTO SOCIO-TERRITORIAL,

ESCALAS DE GESTAO $\mathbb{E}$ INTERORGANIZACGOES

UMA INTRODUĢA

k

o Brasil do século XXI, as organizações vivem em fluxos entrecortados por

instabilidade e ameaças de toda a ordem, bem como por possibilidades utópicas criativas e férteis. Toda a transformação social dirige-se ao idealizado, ao utópico, mesmo que os valores subjacentes sejam discutíveis. Quais sãos os desafios e dilemas de gestão que propõe o desenvolvimento de territórios?

O desenvolvimento em várias escalas (nacional, regional, local) é a utopia mobilizadora que catalisa programas e projetos de governos e sociedade neste início de milênio. Constatam-se ações articuladas entre organizações e entre organizações públicas e privadas, governamentais e não governamentais, na gestão do desenvolvimento territorial.

O território é um campo de forças, ou seja, de exercício de poderes em diferentes escalas, que vão do micro-local ao global. Refere-se a um âmbito espacial delimitado - um bairro, um município, uma região - podendo ainda ser indicado por outras designações que sugerem uma certa inércia, estabilidade e relativa ordenação. Ao se definir um contorno territorial, pressupõe-se um agenciamento estratégico neste recorte. Ou seja, território é concretude e forma, mas também indica movimento e interação de grupos sociais que se articulam e se opõem em torno de interesses comuns.

O território como organização complexa que articula, estrutura e agência (GIDDENS, 1984) em escalas múltiplas tem sido objeto de pesquisa dos pesquisadores articulados pelo Programa de Desenvolvimento e Gestão Social - PDGS1, que estrutura o Centro Interdisciplinar de Apoio à Gestão Social do Desenvolvimento CIAGS.

Desde 1986, estudam-se os poderes espacialmente localizados, discutindose híbridos organizacionais e processos gestionários verificados em várias escalas territoriais. De 1996 a 2002, o objeto dos trabalhos foram as configurações interorganizacionais e as estratégias de institucionalização adotadas por atores e organizações que exerciam liderança em projetos sociais e culturais e em setores de infra-estrutura que dão suporte ao desenvolvimento local. O âmbito destes estudos era a cidade, percebida como rede de fluxos e teia organizacional (FISCHER, 1996; VILLASANTE, 1998; MAC-ALLISTER, 2003).

$\mathrm{Na}$ década de 90 , a hibridização organizacional já era perceptível na estratégia de desenvolvimento local de cidades, como evidenciou a comparação entre os modelos de gestão de Barcelona, Córdoba, Valência e Madri em contraponto a Recife, Salvador, Rio de Janeiro, Curitiba e Porto Alegre (FISCHER, 1996).

$O$ estudo sobre redes sociais realizado por pesquisadores da Universidade Complutense de Madri e grupos de pésquisa de Caracas, Bogotá, Lima, Santiago, Buenos Aires e Salvador, concluído em 1993, já indicava a passagem de um "movimento vicinal" a "vários movimentos cidadãos" (VILLASANTE, 1998).

Houve uma transição perceptível na situação de associações representativas de interesses vicinais para movimentos sociais mais amplos, ou seja, que se identificam com a cidade como espaço para viver, menos singular e mais pluralista, que avançaram da "justaposição defensiva" para a ação coletiva.

A cidade como organização de alta complexidade, considerando a superposição de escalas de gestão, tem sido estudada por Moura (1996), Fischer (1996) e Mac-Allister (2003). Estudos sobre configurações de redes territoriais entre 1990 e 2004 indicaram a multiplicação das interorganizações com este for-

1 O PDGS é financiado com recursos do Fundo Verde Amarelo do MCr/FINEP, CNPq, Fundação de Apoio à Pesquisa da Bahia-FAPESB/SECTI e Fundação Kellogg. 
mato e a afirmação dos territórios - rede, segundo conceito de Haesbart (2004). A articulação de redes mistas entre governo, empresas e associações da sociedade civil foi estudada no contexto de bairros, como o Centro Histórico (HEBER, 1998).

A gestão de serviços públicos reticulados em novos modelos de organização e regulação foram estudados por Fadul (1996) e Fischer et al (2002). As redes de redes foram mapeadas na pesquisa sobre o carnaval baiano, visto como megaorganização (FISCHER, 1996; MIGUEZ e LOIOLA, 1995; FISCHER e GINBO, 1998).

$\mathrm{Na}$ área de estudos sobre governo e cidadania, destacam-se os estudos de Pinho (1997); Pinho e Santana (1997); Pinho (2003), sobre articulação de serviços urbanos municipais e orçamento participativo, os de Fadul (1993 e 2000) e sobre democracia e governança mundial, o trabalho de Milani et al, 2002. A articulação entre empresas e sociedade no desenvolvimento local foi analisada por Schommer (2002); e entre os estudos sobre organizações associativas atuando em escala nacional, destaca-se o de Patiri (2002) sobre o Projeto Tamar.

O foco de análise foi se ampliando e reflete a evolução das formas de ação coletiva conforme se constata nos estudos referidos, desenvolvidos na década de 90 e início desta. Os movimentos sociais que operavam em Salvador no início dos anos 90 eram movimentos de caráter vicinal, como a Associação dos Favelados, que tinham como escala de ação a cidade.

Registra-se, então, uma crise de representação e uma substituição gradativa destas associações por organizações de caráter mais independente, que assumiram um papel mediador entre interesses da sociedade, governos e agências nacionais e internacionais.

As organizações não governamentais, afirmam-se na esteira de políticas sociais sugeridas pela constituiç̧ão de 1988. Na Bahia, as organizações não-governamentais tornam-se protagonistas da cena social, assumindo funções na execução de programas e projetos de políticas públicas, de agentes financiadores nacionais e internacionais e como expressão e afirmação da etnicidade, como foi o caso dos grupos afro-culturais em Salvador. Estes grupos atraem a atenção dos pesquisadores e se projetam internacionalmente como organizações associativas e produtores da cultura com inserção em mercados internacionais, na década de 90.

O Grupo Cultural Olodum foi estudado por Fischer e Dantas (1993) e por Dantas (1994), iniciando uma série de estudos sobre organizações da mesma natureza como o Ylê Aiyê, os Apaches do Tororó, as Organizações Brown, os Filhos de Ghandi (TEIXEIRA e CERQUEIRA, 1996; CASTRO, 1998; FERRAZ, 2001). Estes trabalhos apóiam-se no viés interpretativo de Siqueira (1993) que reconstrói contextos de africanidade na Bahia, bem como nas teorias sobre organizações complexas, especialmente os estudos sobre redes sociais.

O reconhecimento da hibridização destas organizações, representativas de interesses étnico-culturais, contribuiu para a intensificação dos estudos sobre organizações complexas orientadas ao desenvolvimento sócio-territorial.

No âmbito do Programa de Desenvolvimento e Gestão Social (PDGS), iniciado em 2001, as abordagens da gestão do desenvolvimento territorial orientam-se para atores, organizações e interorganizações com diversos graus de imbricamento. Pinho e Aktsu (2003) discutem a sociedade civil e o governo digital. Santos et al (2003) retornam à gestão de serviços ao analisar conflitos na gestão das águas em bacias hidrográficas, perspectiva também adotada por Andrade et al (2003), ao estudarem conflitos da governança na Costa dos Coqueiros na região de Sauípe.

Como se reitera, os poderes locais estão entrelaçados em estratégias orientadas tanto por competição e conflito de interesses, quanto por princípios e práticas solidárias. As formas de gestão verificáveis nas interorganizações com desenhos organizativos complexos conformam uma pedagogia social que permite, ao menos residualmente, a acumulação de um capital cultural estruturante de instituições.

Milani (2002) vale-se das teorias sobre capital social para análise da experiência do município de Pintadas e dos desafios enfrentados nos processos de desenvolvimento local. Na mesma linha de preocupações com capital social, Laniado e Baiardi (2002) tratam das relações entre empresariado e sociedade. 
Desenvolvimento local é revisto como conceitofâncora por Fischer (2002), Moura (2002), Milani (2003) e França (2004). As organizações e interorganizações que dinamizam territórios são "atores estratégicos em campos institucionais"(HENEMANS, 2003).

Analisar organizações complexas orientadas ao desenvolvimento territorial como atores estratégicos remete a questões teóricas sobre como se configuram interorganizações quanto a textura (ou estrutura) e como estas se articulam e se movimentam nos campos delimitados pelos interesses das distintas representações sociais.

As organizações de caráter associativo, não governamentais, são híbridos organizacionais que atuam nos interstícios entre sociedade e mercado; entre governo e sociedade e entre diferentes enclaves sociais. A estas instituições foram delegadas funções de Estado e foram as mesmas guindadas à liderança e representação sociais; substituindo em muitos casos a representação direta dos movimentos sociais.

Este trabalho parte do conceito de estrutura referida às interorganizações, identificando-se totalidade, transformação e auto-regulação como propriedades essenciais de organizações complexas.

Discute-se, após, a estrutura das interorganizações quanto a textura (hibridização) e configurações (redes e redes de redes), bem como o papel das organizações associativas como nós de redes.

$\mathrm{Na}$ intenção de identificar perfis organizativos e articulações interorganizacionais efetivos ou potenciais na construção de interorganizações orientadas ao desenvolvimento no Estado da Bahia, está em desenvolvimento o projeto de mapeamento de organizações de caráter associativo abrangendo 184 municípios.

0 primeiro estudo foi realizado em amostra de 180 organizações não governamentais na capital, Salvador. O estudo descritivo-configuracional realizado em amostra das 180 organizações revela características deste conjunto e questiona se as organizações associativas estão realmente imbricadas em interorganizações orientadas para e pelo desenvolvimento sócio-territorial.

Conclui-se definindo papéis efetivos e potenciais a serem exercidos pelas organizações e interorganizações e renovam-se compromissos com uma agenda de pesquisa.

\section{ESTRUTURANDO INTERORGANIZAÇOER:}

\section{TIEXTURAS $\mathbb{E}$ FORMAS}

As organizações são construções sociais, tecidas pela ação coletiva.

Ao falarmos de construções sociais e texturas organizacionais, falamos de estruturas e de forma maior ou menor complexidade.

Interorganizações são estruturas hibridizadas e, como tal, definidas pelo entrelaçamento (processo) ou tecido (resultado) que se processa quando as organizações trabalham em conjunto, dinamizando territórios.

Por que é importante partir do conceito de estrutura? Estrutura é um dos conceitos mais recorrentes no campo das Ciências Sociais, sendo objeto das teorias clássicas até as hipermodernas. No entanto, a polissemia do conceito, que vai do senso comum até sofisticadas elaborações filosóficas e matemáticas, parece inesgotável. Boudon já observava, em 1968, que: "Parmi des concepts - clés des sciences humaines, le concept de structure est sans doute um des plus obscurs".

Estrutura é um conceito que remete à idéia de forma, de representação, como lembra Sampaio (1999), "a forma expressa sempre um modo de estruturação das coisas, ou seja, alcança vários níveis e escalas de representação das partes ou elementos de um conjunto dado". A forma é a "estrutura revelada" como define Milton Santos (1999). No Dicionário Houaiss, estrutura é conceituada como: "(a) organização, disposição e ordem dos elementos essenciais que compõem um corpo concreto ou abstrato; (b) processo de uma construção; (c) objeto concreto ou construído e (d) modo de construção". 
O conceito de estrutura refere-se explicitamente às partes ou componentes que integram uma totalidade e ao processo contínuo que a mantém constantemente em movimento e transformação. Estruturas não existem no vácuo e, sim, em contextos dinâmicos.

Segundo Jean Piaget (1968), um estruturalista quase ausente nos Estudos Organizacionais, estrutura é:

um systeme de transformations qui comporte das lois em tant que systeme por opposition aux proprietès dês elements et qui se conserve on s'enrichit por lê jeux de transformations sans que celles-ci aboutissent em dehors de sés fronteères. Em um mot, une structure compreend lês trois caractères de totalité, de transformation et d'autorègage (PIAGET, 1968).

Froehlicher e Walliser (2003) refletem sobre totalidade, transformação e autoregulação como características essenciais de estruturas complexas. Segundo a totalidade, os elementos estruturais são diferenciados, mas se subordinam às leis que caracterizam o sistema como tal, conferindo-lhe forma e identidade. Pela característica de transformação, a estrutura não é uma forma estática, mas um sistema de transformações. As totalidades estruturadas estão em constante bipolaridade: são sempre e simultaneamente estruturantes e estruturadas. Quanto à auto-regulação, ela designa a atitude das estruturas a se regular por si mesmas, preservando identidades e limites formais ao tempo em que admitem elementos capazes de renová-los.

As três características - totalidade, transformação e auto-regulação - são recursos conceituais na análise de organizações que se verificam separadamente ou em conjunto desde o início do século $X X$. Desde então, o conceito de estrutura é subjacente às análises e prescrilções dos autores clássicos. Quando Taylor propõe um modelo universal de gestão em que a hierarquia de comando é suposta (o operário está submetido a diversos níveis organizacionais) ou quando Fayol propõe a "unidade de comando", há o reconhecimento de estruturas formais de autoridade.

Nos anos 50 e 60, a idéia de estrutura relativiza-se cada vez mais às circunstâncias e contingências, destacando-se as contribuições de Woodward (1968), Burns e Stalker (1961) e, especialmente, Laurence e Lorsch (1967), com o uso dos conceitos de diferenciação e integração.

Reconhecendo as dimensões humanas nos processos de departamentalização das organizações, os autores insistem nas orientações cognitivas e afetivas sobre os "interesses e opiniões diferentes". A diferenciação não se limita a uma questão de especialização, mas exprime diversidade cognitiva e comportamental; bem como a integração remete à qualidade da colaboração entre os departamentos, o que é também enfatizado por Mary Parker Follet (1973) quando articula os conceitos de poder, descentralização, integração, conflito e solução de problemas, autoridade horizontal e grupos multifuncionais.

Faz-se justiça, assim, aos autores que trataram a organização como estrutura dinamizada por pessoas, já concebida por Weber, no início do século $X X$, como uma estrutura social. Perspectivas de análise estruturalistas e pós-estruturalistas se sucederam, agregando significados e perspectivas de análise às estruturas sociais que foram apropriadas pelos estudos organizacionais. Destas, deve-se destacar a contribuição de Henry Mintzberg (1969) ao estudo de configurações organizacionais.

Mintzberg (1969) estabelece uma tipologia de configurações organizativas, de complexidade crescente. O próprio autor discute as limitações da análise de estruturas organizacionais nos anos 80 afirmando que: " A visão acadêmica sobre organizações tem a tendência de limitar sua visão através do favorecimento da análise em detrimento da síntese". O autor acrescenta que a pesquisa limita-se a "focalizar as variáveis individuais em escalas lineares, em vez de entender como os diferentes grupos de atributos configuram-se em tipo, referidos como configurações, arquétipos ou gestalts". O objetivo do autor é argumentar a favor da existência de configurações organizativas, seja pelas "necessidades das próprias organizações, seja pela necessidade das pessoas que tentam entender as organizações" (MINTZBERG, 1969). 
Organizações complexas sempre existiram e as formas que as tornam visíveis e identitárias também. Talvez o que tenha mudado seja o olhar com que estes fenômenos são vistos, que permite reconhecer a complexidade da textura interorganizacional, muito além da dimensão formal.

Quase quarenta anos separam as duas obras de Amitai Etzioni que tratam das organizações complexas. Em Complex Organizations, editada em 1961, Etzioni seleciona textos de Max Weber, Chester Barnard, Philip Selznick, Talcott Parsons e Peter Blau, entre outros estruturalistas e estruturais-funcionalistas. Mesmo tratando de organizações discretas como empresas, hospitais e sindicatos, os autores reconhecem as dimensões sociais das práticas organizacionais. O estudo de Rossi (1973) discute a estrutura de organização de uma comunidade americana no período, chamando a atenção para o declínio da importância do governo local e a ascensão das associações voluntárias:

Não há dúvidas de que este é o lócus do projeto de comunidade. Empreendimentos comunitários significativos são freqüentemente iniciados fora da estrutura do governo local, ajudados por associações cívicas e comitês de cidadão.

Em 1998, Etzioni coordena outra coletânea - The Essencial Comunitarian Reader - reunindo autores que analisam fenômenos organizacionais identificáveis em comunidades, entendendo que estes fenômenos são embebidos na sociedade. A revisão que Etzioni faz, no final do século, dos conceitos organizacionais ancorados no estrutural-funcionalismo dos anos 60, ao refletir sobre práticas sociais desejáveis na sociedade americana, encontra eco nos autores identificados com teorias de estruturação de vida social como a proposta por A. Giddens e todo - vasto referencial neo-estruturalista do campo da análise de redes sociais.

$\mathrm{Na}$ verdade, a bipolaridade das análises que distinguem estruturas formais das informais é sucedida pela visão interacionista (BURREL e MORGAN, 1989); pela cognitivista (COSSETTE, 2004; WEICK, 2001); pela institucional (SCOTT, 1995), pelas teorias sobre a estruturação (GIDDENS, 1984; CLARK, 2000); pelas teorias sobre configurações organizacionais (DESMERAUX, 1998) e, ainda, pelo vasto referencial neo-estruturalista sobre redes, objeto da parte seguinte deste texto.

Se as teorias clássicas e as que se seguiram (notadamente as contingenciais) exploraram excessivamente a "estrutura de superfície", os vieses institucionalista, construtivista e da estruturação põem forte acento na "estrutura de fundo". Para Bouchikhi (1990), Eraly (1988), bem como para Cossette (2004), não existe uma só estrutura mesmo quando nos referimos a só uma organização, mas estruturas superpostas, imbricadas simétrica ou assimetricamente.

Portanto, qualquer organização tem textura complexa; complexidade que cresce extraordinariamente ao analisarmos interorganizações. As interorganizações são identificadas pela textura, isto é, pelo tecido hibrido formado por organizações que atuam em conjunto. Antonio Strati (2000) chama a atenção para a textura das organizações como uma variável analítica que auxilia na compreensão de organizações complexas.

A tendência apontada por Alter e Hage (1993), a de que cada vez mais as organizações se associam em busca de objetivos comuns, implica a necessidade de modelos de análise para configurações. Organizações confundem-se com os contextos nas quais operam, embebidas nestes, sendo recortes, muitas vezes, superpostos de espaços sociais. Olhar as organizações pela sua textura é uma forma de ver configurações que se constróem, desconstróem e reconstróem em tempos e espaços intencionalmente delimitado pela análise. Segundo Strati (2000), o conceito de textura tem forte poder evocativo. "Um território imaginário, um domínio circunscrito de atores que compartilham idéias, projetos, emoções, sensibilidades, modelos de ação, normas, estilos, códigos de ética, senso estético..."

Ao se falar, portanto, em desenvolvimento territorial e interorganizações, alude-se às tramas e ao conjunto de redes sociais, que se articulam e superpõem, com relações de cooperação ou conflito, em torno de interesses, recursos e valores, em um espaço cujo contorno é definido pela configuração deste conjunto. 


\title{
CONIIGUIRA GOEES INTERORGANIZACIONAIS IE O
} IPAPIE DAS IRAMIAS SOGGIOAPRODUTIVAS NO

\author{
DESENVOIVIMIENTO SOCIAL,
}

A construção social do desenvolvimento local é, então, forjada por interorganizações que refletem os interesses plurais das instituições que operam no espaço público. Governo local, empresas, organizações sociais articulam-se dentro de uma trama singular de interesses criando modelos de ações coletivas, traduzidos em desenhos organizativos complexos, em que o poder flui diferentemente conforme a verticalização ou horizontalização das relações, guardadas as contradições destes processos e jogos de interesses dos atores (FISCHER, 2002).

A transversalidade ou a complexidade das relações entre dominantes e dominados - com tensões, avanços e recuos permanentes, com ganhos e perdas reais e simbólicas que podem ser avaliados diferentemente conforme a perspectiva - faz com que se reconheça a crescente pluralidade do poder espacialmente localizado, exercido nos chamados espaços públicos.

Sainsaulieu (2001) chama a atenção para as diferenças entre a situação em que há necessidade de aliançaś de negociação e de regulação e aquelas em que os jogos de poder conduzem a exigências de dominação, de contrapoder ou a antagonismos recorrentes. No primeiro caso, pode-se chegar a formas de cooperação aceitáveis entre atores, grupos e organizações. No segundo caso, os individuos e coletivos chegarão à confrontação, conflito, ou usarão estratégias de ignorância mútua. As situações concretas de gestão social podem produzir crises ou identidades no firmar acordos e regulações sociais legítimos (SAINSAULIEU, op. cit.).

Complexidade e diferenciação/conexão são chamados de propriedades estruturais das interorganizações por Alter e Hage (1993), agregando a essas duas a centralidade, que depende de coordenação ou gestão.

Articulação estratégica é o ponto focal do conceito. Desenvolvimento compreende, ao mesmo tempo, processos compartilhados e resultados atingidos; visões de futuro ou utopias construídas por coletivos organizacionais e ações concretas de mudança. Trata-se, portanto, de estratégias processuais, isto é, que se inscrevem no paradigma da racionalidade processual e contextual (MARTINET e THIETHART, 2001). Estratégias processuais - ou tateantes, na concepção de Avenier (1997) - "são ações orientadas a fins potencialmente evolutivos, estabelecidos dentro de uma dialética permanente entre meios e fins em contextos que permitem o uso dos meios e a consecução dos fins". Aceitando-se esse conceito, visão e ação estratégica são, simultaneamente, processo e resultado, concretude e utopia, atendendo aos princípios de totalidade, transformação e auto-regulação, citados anteriormente.

Portanto, processos de gestão verticais, horizontais ou transversais exercidos em escalas territoriais variáveis ocorrem em organizações e interorganizações por meio de ações articuladas cooperativas e/ou competitivas, como ilustrado a seguir.

Interorganizações atuam sobre escalas territoriais que vão de micro-local ao internacional e global, de forma sincrônica. Interorganizações têm texturas e configurações diversas desde organizações hibridizadas, como as ONGs, até o formato em rede. Estas interorganizações podem se converter em redes de redes, quer para a mobilização coletiva, quer para compartilhar e difundir informações, concretizadas em websites como o portal www.gestaosocial.org.br

Fóruns em escala regional, nacional ou internacional para a promoção de desenvolvimento territorial assumem formas diversas, tais como os consórcios intermunicipais. São exemplares os fóruns de economia solidária de âmbito nacional e estadual e os chamados sistemas produtivos locais.

Yoguel, Novick e Martin (2001) referem-se aos conjuntos de "agentes interrelacionados" (clusters, sistemas locais ou milieu), presentes na literatura sobre as novas formas de organização dos sistemas produtivos, e propõem o conceito 
de "trama produtiva", isto é, de articulação entre "agentes de desenvolvimento, atividades inovadoras e tecnologias de gestão social, o que inclui a organização do processo de trabalho e o modelo de relaçõẹs trabalhistas vigentes" (YOGEL et al, apud GUIMARÃES e MARTIN, 2001).

A expressão mais recente das tramas produtivas é o "arranjo produtivo local" (APL), desenvolvida pela Redesist (Lastres e Cassiolato, 2002) e incorporada em políticas do governo brasileiro no âmbito federal (Ministério de Integração e de Ciência e Tecnologia, entre outros), nos estados e municípios. O sistema $S$, especialmente o SEBRAE, bem como agências (como a SUDENE) e bancos de desenvolvimento adotaram os APLS como estrutura em rede, bem como governos estaduais e municipais.

Como os próprios autores Lastres e Cassiolato (2002) argumentam, "o foco em APLs não deve ser visto como prioridade política e sim como um formato que potencializa ações de promoção por focalizar agentes coletivos, seus ambientes, capacidades e requerimentos" (grifo nosso).

Se, por um lado, estimulam-se arranjos produtivos nos âmbitos federal, estadual e municipal como a forma mais adequada de agenciamento do desenvolvimento territorial e os territórios são recortados como APLs (como é o caso da Bahia, onde foram definidos 15 arranjos produtivos), empreendimentos de Economia Social ou Solidária são apoiados pelos mesmos governos. O governo federal estimula APLs no Ministério de Integração Nacional e Ministério de Ciência e Tecnologia, mas há também uma Secretaria de Economia Solidária, ligada ao Ministério do Trabalho.

Sob a designação de empreendimentos solidários podem-se nomear formas associativas de produção promovidas por ONGs, comunidades, movimentos sociais e setores governamentais; dinâmicas locais de orientação ecológica e sustentável (a despeito das críticas e dissensões); movimentos feministas, voltados para a inclusão das mulheres nos processos de desenvolvimento; mecanismos para concessão de microcrédito e, finalmente, movimentos sociais em prol dos direitos à terra e à habitação (FRANÇA, 2004; 2003; 2002).

Conforme distinção feita por Gaiger (2004),

a economia solidária apresenta-se como um campo de construção de alternativas econômicas ao modelo dominante, alicerçadas em discurso crítico transformador e em práticas solidárias e autogestionárias, muito próximas dos movimentos sociais.

Pesquisa do governo do estado da Bahia registra a existência de 38 empreendimentos solidários na região metropolitana de Salvador e litoral norte da Bahia (SEI, 2004).

Confrontadas as vertentes da competitividade e da solidariedade, há diferenças óbvias e superposições também óbvias entre o que se pode chamar de perspectivas de ação. Nos dois sentidos, pressupõe-se a existência de organizações complexas - interorganizações - e estratégias processuais. As diferenças encontram-se no papel e no peso dos atores envolvidos nas formas de gestão e nos valores de fundo que orientam as duas perspectivas. Mesmo percebendo-se essas diferenças, não é trivial distinguir tais processos nas práticas sociais, correndo-se o risco de um maniqueísmo redutor. Nos argumentos de uns e outros, são comuns os ideais utópicos de construção social de um futuro melhor. Sem dúvida, a Economia Solidária enfatiza redistribuição e reciprocidade (LAVILLE, 2000), bem como rediscute o espaço público como espaço social, mas cabe ressalvar que a retórica que sustenta os sistemas produtivos não descarta o social, como pode ser constatado no documento do SEBRAE sobre territórios de baixa densidade empresarial (SEBRAE, 2003), ou mesmo no documento sobre o desenvolvimento de distritos industriais (SEBRAE, 2003) que apresenta o Programa APL como "parte de um programa redistributivo".

A figura 1 ilustra a indissociabilidade entre configurações organizacionais e interorganizacionais, processo de gestão e as escalas territoriais em que são exercidos, representando as texturas referidas. 
Figura 1 - Tramas Sócio-Produtivas, Processos de Gestão e Escalas de Poder

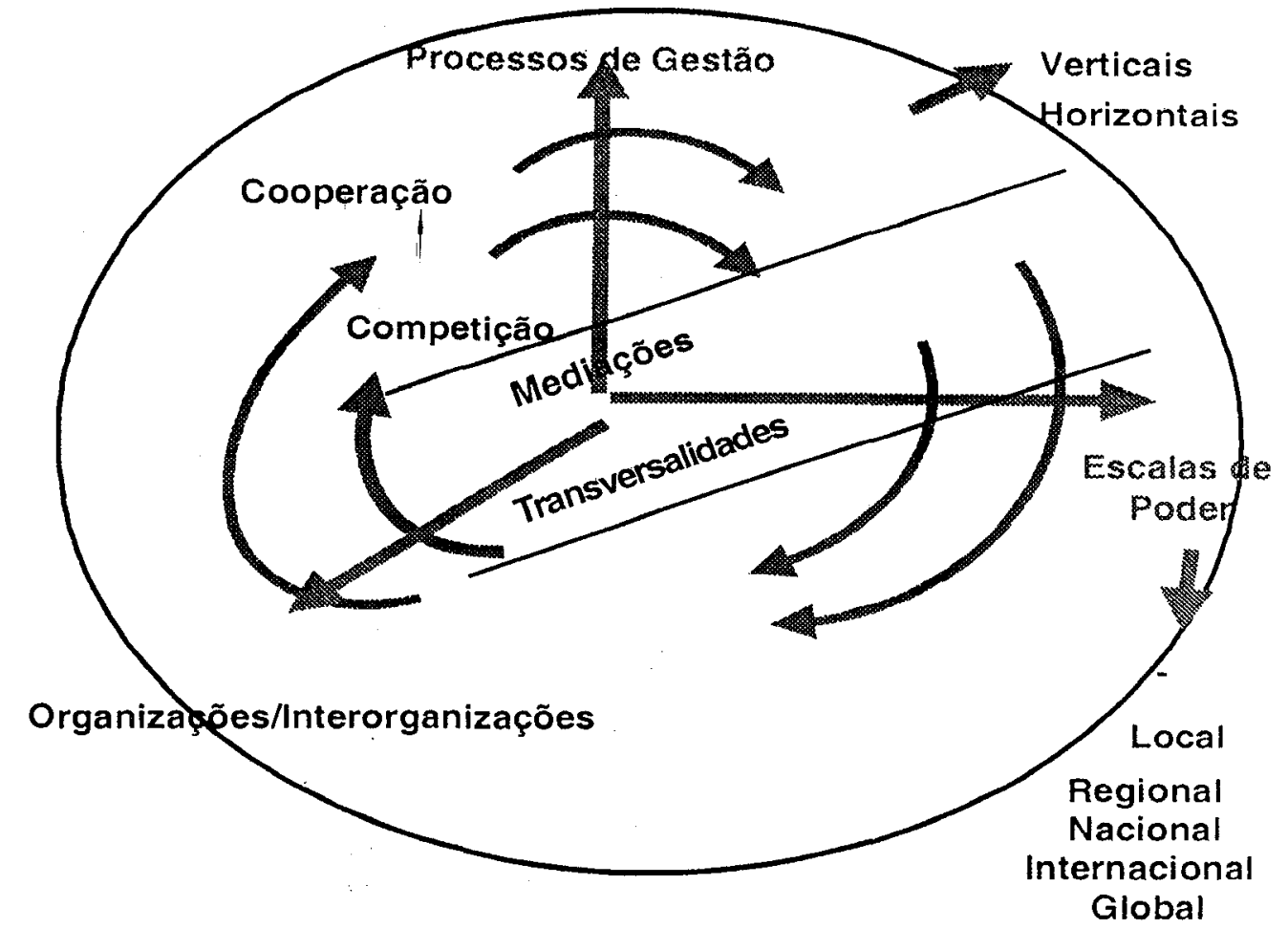

Fonte: Elaboração própria

Os conceitos de Mediações e Transversalidade são comuns às configurações organizacionais e interorganizacionais complexas. As mediações são realizadas por atores sociais, entendidos como indivíduos ou instituições gestoras.

Cooperar e competir são agenciamentos polares, mas não excludentes nás políticas de gestão territorial. Temos aí um duplo movimento da parte ao todo e do todo (escala internacional e global) às partes, ao local. As disputas por recursos e as estratégias de sustentabilidade levam, inevitavelmente, à competição. De outra parte, as associações entre iguais e diferentes são orientadas por lógicas de cooperação, formando-se alianças, parcerias, pactos, consórcios.

Os processos de gestão em organizações complexas fluem em diferentes direções - verticais, horizontais, transversais -, pois, organizações e redes organizacionais encontram-se para cooperar, mas, em paralelo, estabelecem convenções para mitigar efeitos e regular competição. A transversalidade dos processos de gestão ocorre entre organizações/interorganizações, entre escalas de poder, entre movimentos de natureza mais cooperativa ou competitiva. A transversalidade é propriedade das redes, metáfora mais recorrente no estudo de tramas sócio-produtivas.

As redes são um tipo de textura, com conotação substantiva (totalidade), supondo permanente movimento, entrelaçamento (transformação) e tensões entre estabilidade e mudança (auto-regulação), com as características de sistema identificadas por Jean Piaget.

O termo rede deriva do latim rete, que significa entrelaçamento de fios, cordas, cordéis, arames, com aberturas regulares fixadas por malhas, formando uma espécie de tecido. Dois elementos essenciais compõem as redes - as linhas e os nós - não havendo diferenças hierárquicas entre eles, mas apenas de função (ligação e sustentação, respectivamente) (MOURA, 1997).

Utilizam-se aqui os conceitos de rede de Degènne (2004) e Villasante (1998) que, em escalas diferentes, pensam esta forma de articulação social. Degenne refere-se a um 
conjunto de círculos sociais pré-constituidos e mais ou menos estruturados, a que pertence o indivíduo - família, trabalho, localidade - e, em conseqüência, redes mais complexas, que se configuram pela interseção dos conjuntos de círculos sociais que têm a ver com a questão em foco...

E conclui... "pensar desta forma (em rede) é uma maneira de abordar os grupos sociais localizados".

Villasante (1998) conceitua rede como o conjunto de relações que se podem identificar entre diversos coletivos, gerando o chamado tecido social associativo: "Quando falamos de tecido social, de rede social, não nos referimos a vínculos simbólicos apenas, mas a comportamentos que se mantêm em uma estrutura social estável". O termo rede é utilizado pelo autor para caracterizar as relações objetivas que ocorrem na prática social localizada.

John Scott e Alain Degènne publicam em 2000 e 2004, respectivamente, sinteses do "estado de arte" no campo das redes sociais. Representantes das vertentes anglo-saxônica e francofônica, os autores têm em comum o reconhecimento da estrutura como ponto focal das redes.

Nos estudos sobre redes encontram-se tanto a reflexão sobre redes de atores sociais e seus significados na sociedade contemporânea, tais como os desenvolvidos por Lemieux (1999), Parrochie (2001) e Musso (2003), quanto o viés metodológico das possibilidades analíticas da análise de redes sociais desenvolvidas por Alter e Hage (1993), Kilduff (2003), Degènne e Torsé (2004).

A análise de redes tem sido objeto de estudos no Brasil, ora utilizada como representação de organizações complexas, ora como método (MACHADO-DA-SIL VA, 2000; COSER, 2004). A representação de redes evidencia duas características: (a) a diversidade dos componentes estruturais (nós) e (b) a importância das relações (linhas); as quais transparecem nos estudos de Robert Putnam sobre capital social (PUTNAN, 1993); de Degènne e Torse (2004) sobre práticas associativas; de Lemieux (1999) sobre redes associadas às políticas públicas; e de Gaudin (2003) sobre desenvolvimento local e gestão territorial.

A diversificação das redes voltadas para a mobilização de comunidades é refletida nas adjetivações que as tipificam: redes sistêmicas (ALTER e HAGE, 1993); redes estratégicas e de solidariedade (RANDOLPH, 1993 e 1994 apud MOURA, 1997); redes de inserção local (MAUREL, 1991 apud MOURA, 1997) e redes de movimento (SCHERER-WARREN, 1999), estas como tramas de alta complexidade interorganizacional.

Como se configuram as interorganizações que atuam no desenvolvimento de territórios? Podemos representá-las pela figura abaixo, como uma rede em três niveis de complexidade: o primeiro nivel é o das organizações; o segundo, das formas organizacionais articuladas em redes; e o terceiro, das redes de redes. 
Figura 2 - Interorganizações em Rede e Desenvolvimento Territorial

Fonte: Elaboração própria

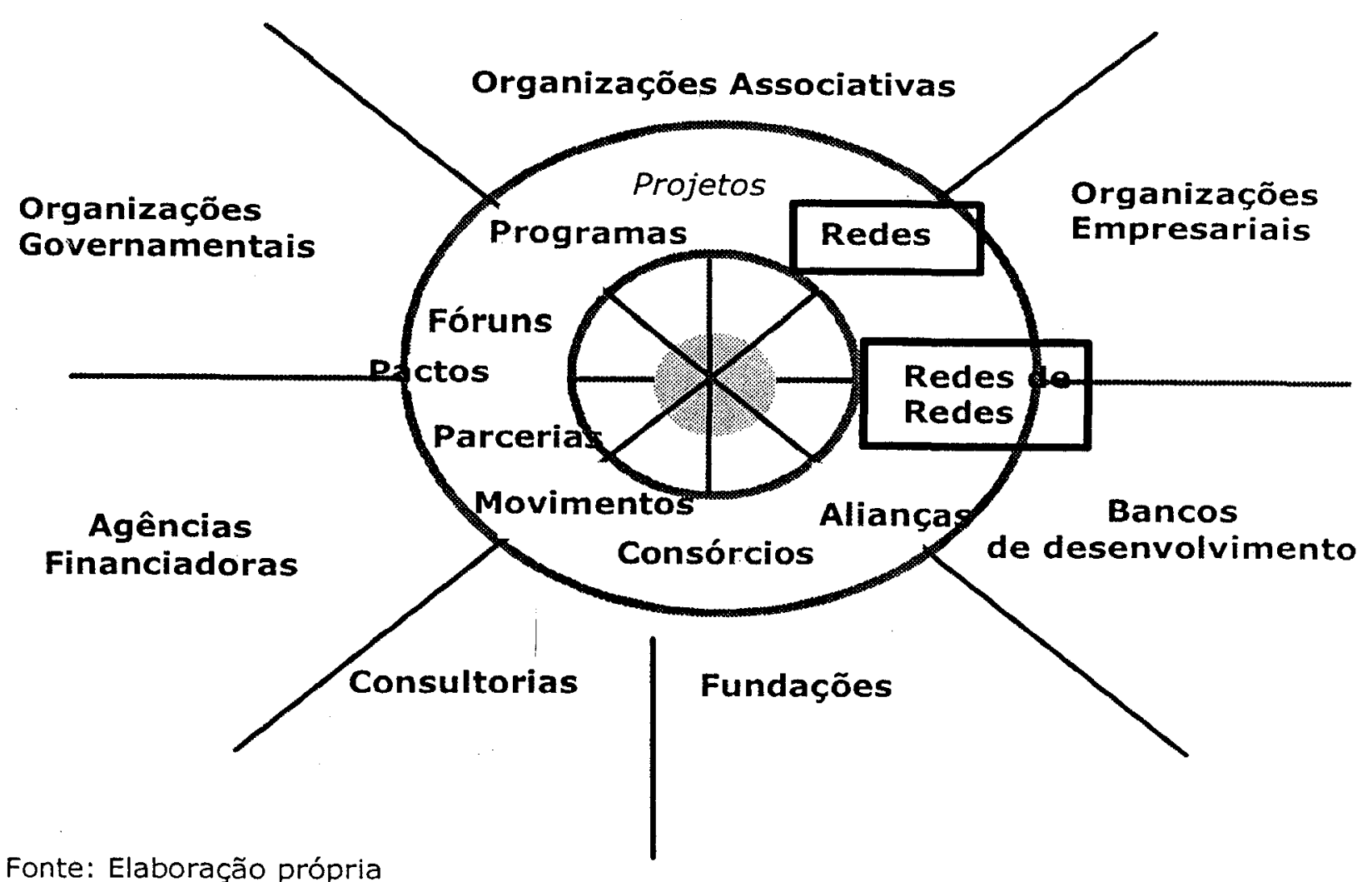

Organizações de primeiro nível são as organizações associativas, organizações de governo e empresas, bem como agentes financiadores, consultorias, fundações, bancos de desenvolvimento e outras organizações discretas, que desenvolvem ações estratégicas sobre o território. Assumindo a forma de programas e projetos conjuntos, parcerias, cooperativas, as organizações articulam-se em um segundo nivel: o das redes.

Organizações associativas podem articular redes temáticas entre si, focalizando temas específicos como saúde, infância, gênero etc. Podem também articular redes na forma de parcerias e alianças no desenvolvimento de programas e projetos, que contam com ONGs como nós de tramas sócio-produtivas.

As redes de redes têm um grau maior de complexidade e podem ser representadas por fóruns e consórcios, associados a recortes territoriais na forma de arranjos sócio-produtivos a espaços virtuais (websites).

A ação das ONGs em rede supõe configurações articuladas e ações estratégicas compartilhadas. Por exemplo, uma ONG pode ter como área de abrangência um recorte territorial como um bairro, uma favela, um logradouro e se articular em parcerias para desenvolver programas setoriais que abranjam a cidade (mesolocal) ou uma área metropolítica (macrolocal).

A mesma ONG pode integrar um fórum regional e fazer parte de alianças e movimentos nacionais e internacionais. As organizações de caráter associativo designadas por ONGs são atorles paradoxais na articulação de interorganizações orientadas ao desenvolvimento.

A seguir, discute-se o conceito, tipologias e formas interorganizacionais que podem ser encontradas no universo das ONGs. 


\section{As ONGS COMO Nós DE Tramas SÓCIO- PRODUTIVAS}

As ONGs desafiam os pesquisadores e têm merecido análises reiteradas como as de Carvalho (2000); Alves (2002); Teodósio (2001) e Carvalho-Ferreira (2004), entre outros. Tendo presença e reconhecimento social tão forte, é de surpreender que seja uma organização que se defina por negação e exclusão. Ao se dizerem "não governamentais", as ONGs colocam-se em posição de autonomia em relação ao Estado. O mesmo ocorre com empresas das quais se distinguem conceitualmente ao se assumirem como "não lucrativas".

O mundo das ONGs não representa uma "dimensão autônoma da sociedade" (SORJ, 2004), pois, na verdade, tem múltiplas e profundas imbricações com diferentes escalas e representações sociais, aí considerados o Estado e o mercado. No seu próprio discurso, as ONGs definem-se como tendo

um perfil político caracterizado por tradição de resistência ao autoritarismo, contribuição à consolidação de novos sujeitos políticos e movimentos sociais, busca de alternativas de deșenvolvimento ambientalmente sustentáveis e socialmente justas, compromisso de luta contra a exclusão, a miséria, as dẹsigualdades sociais, promoção de direitos, construção de cidadania e da defesa da ética na política para a consolidação da democracia (ABONG, Carta de Princípios, 2002).

A fragmentação e diversidade das organizações sem fins lucrativos, em geral, e das ONGs, em particular, são consideráveis, compativeis com a polissemia do conceito. Antigas organizações de caráter filantrópico, associações e clubes de bairro, organizações religiosas, de atenção à saúde, sindicais, artísticas, fundacionais mantidas com recursos privados podem ser enquadradas como ONGs, quer pelos critérios do IBGE, através do CNAE (Classificação de Atividades Econômicas), quer pelo Ministério do Trabalho e Emprego através do RAIS (Relação Anual das Informações Sociais), quer pelo Cadastro Nacional de Pessoal Jurídica - CNPJ da Receita Federal.

Atualmente, projetos de lei prevêem regularizar as ONGs por meio de registro e maior controle, mas há resistências. A trajetória do conceito e das práticas explica a diversidade. Herbert de Souza (s.d. apud SANTANA, 1992) aponta o periodo entre os anos 1960 e 80 como o marco do surgimento das organizações não governamentais brasileiras, nascidas em função da luta política da sociedade civil contra o regime autoritário, da ditadura militar, que se implantou em 1964. Neste contexto, atuavam muito próximo da clandestinidade, ligadas a movimentos sociais de base, Igrejas, movimentos sindicais e populares. Tinham uma ênfase claramente de oposição em relação ao governo, expressa na terminologia "não governamental" (ONG).

No processo de surgimento das organizações não governamentais, também teve papel fundamental a influência de organismos internacionais. Medina (1997) observa que em 1950-60 organismos internacionais começaram a fomentar um processo de desenvolvimento comunitário em países do Terceiro Mundo, pressupondo níveis maiores de participação da comunidade. Dentre eles, pode-se destacar: a Organização das Nações Unidas (ONU), criada após a II Guerra Mundial; - Programa de Desenvolvimento das Nações Unidades (PNUD); o Banco Mundial; - Banco Interamericano de Desenvolvimento (BID); o Fundo das Nações Unidas para a Infância (UNICEF); a Comissão Econômica para a América Latina e o Caribe (CEPAL). Estes organismos internacionais legitimaram as organizações não governamentais, pregaram a necessidade de apoio político e popular e o fortalecimento da administração local para concretização do plano de desenvolvimento.

$\mathrm{Na}$ prática, todo esse aparato era criado e imposto pelos organismos, via controle técnico, econômico, ideológico e político. Os recursos financeiros eram, freqüentemente, condicionados a prazos, cláusulas de compra de pacotes tecnológicos e contratação de consultores estrangeiros, pondo em xeque a so- 
berania nacional. Houve, ainda, uma homogeneização das políticas por diversos países e, conseqüentemente, inadequações, uma vez que as realidades são distintas. Outra crítica feita é que, por serem assistencialistas, as políticas atacaram os efeitos dos problemas, não as causas. Por outro lado, houve um aumento da capacitação de agentes sociais no trabalho comunitário.

Além de contextualizar o papel dos organismos internacionais, Medina (1997) analisou o perfil das organizações não governamentais ao longo do tempo na América Latina. Gohn (1997) também fez uma análise neste sentido, voltada para a realidade brasileira especificamente, e coloca que, nos anos 90, as ONGs ganharam importância por serem potenciais parcerias do poder político, em decorrência de sua estruturação. Esta relação de parceria passou a ser estimulada, uma vez que o discurso neoliberal pressupõe a retirada do Estado de uma série de atividades e a primazia do mercado. Ainda segundo Gohn (1997), nessa mesma época, houve uma reconfiguração do modelo de financiamento às ONGs, do assistencialismo à auto-sustentabilidade. Observa-se um fortalecimento das estruturas nacionais com a criação da ABONG (Associação Brasileira de ONGs) e da CMP (Central de Movimentos Populares), bem como o desenvolvimento de movimentos internacionais no Brasil, a exemplo da ONG ambientalista Greenpeace.

O foco de ação das ONGs e dos movimentos sociais também sofre mudanças: da luta por transporte, saúde, educação e moradia para a luta pela sobrevivência física (alimentos e terra); luta por moral e ética política; luta por direito à pluralidade (movimentos de gênero, raça e idade), luta por uma participação na política direta institucionalizada; perspectiva de parceria, não de oposição ao governo; e políticas formuladas para segmentos sociais. Gohn acrescenta que, apesar de apregoarem autonomia e independência em relação ao Estado, os fundos políticos permanecem como os grandes financiadores de suas demandas.

Verifica-se que a atuação da sociedade civil organizada tomou um rumo diferente, voltada agora não mais para a luta contra o autoritarismo do Estado, como ocorria nos anos 1960-80, mas para a democratização da sociedade (RANDOLPH, 1990 apud SANTANA, 1992). O contexto dos anos 90 colocou em evidência as organizações da sociedade civil, provavelmente, em decorrência das suas próprias conquistas e do fortalecimento da perspectiva de parceria entre as esferas do Estado, mercado e sociedade civil organizada, sendo-lhes delegada a tarefa de construir "novas transversalidades entre espaços institucionais fragmentados" (MEISTER, 2001).

Dentre as tentativas de categorização das ONGs pode-se destacar a de SORJ (2004), que as discrimina segundo fontes de financiamento: PIONGS (ligadas a instituições públicas); BONGS (associadas a empresas); IONGS (relacionadas a redes internacionais); RONGS (ligadas a instituições religiosas) e PONGS (associadas a partidos).

Meister (1992) concorda que o universo é um verdadeiro mosaico e, deve se reconhecer, torna-se muito mais complexo quando estas organizações atuam em conjunto, em alianças, parcerias e redes de modo geral.

Scherer-Warren (1999) contribui bastante para uma percepção das redes na perspectivas das relações interorganizacionais. Analisando a realidade na América Latina, Scherer-Warren propõe uma classificação para as redes considerando os diversos tipos de articulação envolvendo ONG's:

a) Redes temáticas: as organizações são conectadas em torno de temas específicos, como ecologia, saúde, mulher, negro, infância etc;

b) Fóruns de ONG's: as ONG's de determinada região (escalas local, regional, nacional ou mesmo mundial) articulam-se através de seus representantes para a discussão coletiva de programas de ação, estratégias, projetos comuns etc;

c) Associação de ONG's: várias ONG's se filiam a uma associação para se articularem e promoverem intercâmbios, semelhante ao que ocorre nos fóruns. Neste caso, contudo, há uma maior institucionalização; 
d). Redes de informação e de reflexão: criadas para a difusão de informações para ONG's, movimentos sociais e cidadãos, a exemplo das agências alternativas de noticias, boletins eletrônicos, websites diversos, publicações etc. São exemplo a RITS - Rede de Informação sobre Terceiro Setor (www.rits.org.br) e o ISTR - Internacional Society for Third Sector Research (www.istr.org.br);

e) Interface de experiências: significa a união de ONG's locais, representantes de problemas diversos, para o desenvolvimento de um projeto comum (ex.: projeto de reforma urbana). Este tipo de rede se assemelha bastante ao fórum de ONG's, porém, não é uma articulação esporádica.

Como nós de tramas organizativos, as ONGs muitas vezes impulsionam processos transversais, em outros casos, nascem e se legitimam em decorrência de ações transversais de coordenação múltiplas (pactos, consórcios, fóruns).

As ONG's que participam de redes podem participar de múltiplas redes simultaneamente. Desde modo, ocorre um fenômeno de articulação que assume a forma de uma rede de redes e podem configurar movimentos sociais.

$\mathrm{Na}$ intenção de sistematizar as diferenças entre ONGs em rede, o quadro abaixo categoriza redes de ONGs por tipos, natureza, formas de agir e intervir em territórios e escalas predominantes, integrando referências teóricas e empíricas.

Quadro 1 - Interorganizações: ONGs em Rede

\begin{tabular}{|c|c|c|c|c|}
\hline $\begin{array}{l}\text { CONCEI- } \\
\text { TOS- } \\
\text { CHAVE }\end{array}$ & $\begin{array}{l}\text { TIPOS DE } \\
\text { REDES }\end{array}$ & NATUREZA & $\begin{array}{c}\text { TIPOS DE } \\
\text { AÇÕES/ } \\
\text { INTERVENÇÕES }\end{array}$ & ESCALAS \\
\hline \multirow{4}{*}{$\begin{array}{l}\text { Mediações } \\
\\
\text { Transversa- } \\
\text { lidade }\end{array}$} & \begin{tabular}{ll}
\multicolumn{2}{l}{ Setoriais: } \\
- & Saúde \\
- & Gênero \\
- & Etnicidade \\
- & Ambiente \\
- & Habitação
\end{tabular} & $\begin{array}{ll}\text { - Assistência/ } \\
\text { Promoção } \\
\text { Social } \\
\text { Representa- } \\
\text { ção } \\
\text { Geração de } \\
\text { Emprego e } \\
\text { Renda }\end{array}$ & $\begin{array}{c}\text { Ações } \\
\text { Projetos } \\
\text { Programas }\end{array}$ & $\begin{array}{c}\text { Local } \\
\text { Regional } \\
\text { Internacio- } \\
\text { nal } \\
\text { Global }\end{array}$ \\
\hline & De informação & $\begin{array}{ll}\text { - } & \text { Comunica- } \\
\text { ção } \\
\text { - Intercâm- } \\
\text { bio } \\
\text { - Serviços }\end{array}$ & Websites & $\begin{array}{c}\text { Transesca- } \\
\text { lares }\end{array}$ \\
\hline & $\begin{array}{l}\text { De articulação } \\
\text { /De movimen- } \\
\text { tos }\end{array}$ & $\begin{array}{ll}\text { - } & \text { Assistência } \\
\text { - Serviços de } \\
\text { Infra-estru- } \\
\text { tura } \\
\text { Emprego e } \\
\text { Renda }\end{array}$ & $\begin{array}{l}\text { - Parcerias } \\
\text { - Pactos } \\
\text { - Consórcios } \\
\text { - Fóruns }\end{array}$ & $\begin{array}{c}\text { Transesca- } \\
\text { lares }\end{array}$ \\
\hline & $\begin{array}{l}\text { De intervenção } \\
\text { Territorial }\end{array}$ & $\begin{array}{l}\text { Desenvolvi- } \\
\text { mento } \\
\text { Sócio- } \\
\text { Territorial }\end{array}$ & $\begin{array}{ll}\text { - } & \text { Consórcios/Fó- } \\
\text { runs/Pactos } \\
\text { - Arranjos } \\
\text { Sócio- } \\
\text { Produtivos } \\
\text { Fóruns de } \\
\text { Economia } \\
\text { Solidária } \\
\end{array}$ & $\begin{array}{l}\text { Local } \\
\text { Regional } \\
\text { Nacional }\end{array}$ \\
\hline
\end{tabular}

Fonte: Elaboração própria 
O estudo empírico apresentado a seguir pretende esclarecer melhor o perfil organizativo de uma amostra de 180 ONGs de Salvador, Bahia, e se orienta pelas seguintes questões:

a) As ONGs respondem aos critérios de totalidade, transformação e autoregulação das estruturas complexas?

b) Como as ONGs da cidade do Salvador integram redes e redes de redes? Existem conexões que as justifiquem como interorganizações elas próprias ou como elos de redes sociais e de cadeias sócio-produtivas?

São perguntas que se pretende responder ao mapear organizações associativas de Salvador, como se verá a seguir.

\section{PERIIS ORGANIZACIONAIS $\mathbb{E}$ TIRAMAS INTERORGANIZACIONAIS NO UNIVIRSO ASSOCIA $\mathbb{I} \mathbb{V} O$}

Foi realizada em Salvador/Bahia uma pesquisa do tipo survey, que assemetha-se ao censo, mas aplica-se a uma amostra da população, com o objetivo de descrever e, a partir de uma análise multivariada das respostas, de explicar algumas evidências obtidas na pesquisa. Tal survey pode ser classificado com interseccional, pois os dados foram colhidos num momento específico para descrever uma população maior, neste mesmo momento (BABBIE, 1999).

A partir de uma revisão crítica dos dados tabulados, foi necessário ratificar ou retificar algumas respostas a fim de garantir a fidedignidade e a qualidade da pesquisa. Esta etapa foi realizada através de telefonemas ou visitas a determinadas organizações. Um total de 180 organizações constituiu o cadastro de organizações pesquisadas. Finalmente, foi realizada uma análise quantiqualitativa dos resultados obtidos, com apoio estatístico e a utilização do software Sphinx Léxica.

Conforme os tipos organizacionais, as organizações se classificam em:

Tabela 1 - Tipos de Organizações Pesquisadas

\begin{tabular}{l|r|r}
\hline \multicolumn{1}{c|}{ Tipo de Organização } & \multicolumn{1}{c}{ Quant } & \multicolumn{1}{c}{$\%$} \\
\hline Sociedade civil sem fins lucrativos ou associação civil sem fins & 102 & 56,7 \\
lucrativos & 32 & 17,8 \\
Igrejas ou associações religiosas & 19 & 10,6 \\
Sindicatos ou associações profissionais & 06 & 3,3 \\
Institutos privados & 05 & 2,8 \\
Federações ou congregações & 04 & 2,2 \\
Fundações privadas & 01 & 0,6 \\
Partido político & 09 & 5,0 \\
Não possui registro na Receita Federal (CNPJ), ou seja, não são & \\
legalizadas & 02 & 1,1 \\
Programa/projeto independente (ligado a uma organização formal & & \\
para fins de gestão financeira de recursos) & 180 & 100 \\
\hline
\end{tabular}

Quanto à abrangência geográfica das ações, a maioria das organizações atua no âmbito estadual (39,4\%), o que é compreensivel uma vez que a pesquisa foi realizada na capital do Estado da Bahia e que a grande parte das organizações de atuação nacional e internacional encontra-se no eixo Rio de Janeiro-São Paulo. No âmbito nacional, atuam $18,3 \%$ das organizações; $16,7 \%$ atuam no âmbito 
municipal; $16,1 \%$, na própria comunidade onde a organização está situada - em geral, associações de bairro ou comunitárias; $5,6 \%$ atua internacionalmente e $3,9 \%$ atua na Região Metropolitana de Salvador (10 municípios).

Em relação às áreas de atuação das organizações foram dadas múltiplas respostas. Apenas 15 organizações pesquisadas apontaram apenas uma única área de atuação. As demais apontaram duas ou mais áreas de atuação. Pode-se inferir que dificilmente uma organização da sociedade civil fica restrita a apenas uma área de atuação na medida em que a percepção sobre o beneficiário tende a ser integral. A maioria das entidades atua na área de Educação, Profissionalização e/ou Capacitação, perfazendo um total de $70 \%$. Uma análise léxica dos exemplos de projetos fornecidos pelas organizações mostra que a palavra "educação" é a que mais aparece, seguida de "criança", "capacitação" e "curso". No âmbito dos serviços prestados pelas organizações, também foram fornecidas respostas múltiplas. Apenas 18 organizações pesquisadas apontaram apenas um único tipo de serviço prestado. As demais apontaram dois ou mais tipos de serviços.

O público-alvo atendido pelas organizações, assim com as áreas de atuação e os serviços prestados, também podem ser diversificados. Do total pesquisado, 48 organizações atuam com apenas um público-alvo específico. Deste número, 18 organizações atendem à sociedade em geral, 10 atendem a moradores do local e sete atendem à classe trabalhadora, categorias que são abrangentes por si só.

Sobre o perfil de trabalhadores das entidades, verificou-se que $40,6 \%$ das organizações não possuem contratados no seu quadro de pessoal. Das organizações que possuem mais de 100 voluntários, mais de $60 \%$ têm cunho religioso.

Em relação ao orçamento anual das organizações (ano base: 2001), 32,2\% dos entrevistados não quiseram revelar a informação - esta foi a questão com maior índice de não resposta. Cerca de $5,6 \%$ das organizações trabalham com um orçamento inferior a 10 mil reais; $14,4 \%$ têm um orçamento entre $R \$ 10$ e $R \$ 50$ mil; $12,8 \%$, maior ou igual a $\mathrm{R} \$ 50$ e menor que $100 \mathrm{mil} ; 8,3 \%$ têm um orçamento entre $R \$ 100$ e $200 \mathrm{mil} ; 10,6 \%$, entre 200 e $500 \mathrm{mil} ; 7,2 \%$ trabalham com recursos financeiros iguais ou superiores a $R \$ 500$ mil e inferiores a $R \$ 1$ milhão e $8,9 \%$ trabalham com $R \$ 1$ milhão ou mais.

Em se tratando das relações interorganizacionais, apesar de evidenciarmos a sua importância no campo das organizações da sociedade civil, verifica-se que ainda existem organizações $(11,7 \%$ ) que afirmaram não trabalhar em parceria com outras para desenvolverem ações e projetos. As demais organizações estabelecem parcerias conforme o tabela abaixo:

Tabela 2 - Perfil das Relações de Parcerias Estabelecidas pelas Organizações Pesquisadas

\begin{tabular}{l|c|c}
\hline \multicolumn{1}{c|}{ Organizações Parceiras } & Quant. & $\%$ \\
\hline ONGs, associações ou organizações comunitárias & 99 & 55,0 \\
Órgãos da administração pública municipal & 80 & 44,4 \\
Órgãos da administração pública estadual & 78 & 43,3 \\
Empresas privadas & 69 & 38,3 \\
Órgãos da administração pública federal & 56 & 31,1 \\
Redes, fóruns ou federações de organizações & 49 & 27,2 \\
Organismos internacionais & 38 & 21,1 \\
Sindicatos ou associações profissiọnais & 38 & 21,1 \\
Empresas públicas & 34 & 18,9 \\
Outros & 19 & 10,6 \\
Nenhuma & 21 & 11,7 \\
\hline
\end{tabular}

Fonte: Pesquisa direta. 
Apenas 27 organizações das que realizam parceria mencionaram somente um tipo de organização parceira; todas as outras estabelecem parceria com dois ou mais tipos organizacionais distintos e, portanto, marcaram mais de uma opção na questão sobre organizações parceiras.

Dos organismos internacionais mencionados, destacam-se a União Européia, com quatro respostas, a Ágata Esmeralda (Itália) e a Misereor (Alemanha), atuando em parceria com três organizações, e organismos como Childhope (Inglaterra), Adveniat (Alemanha), Handicap International, Ministério das Relações Exteriores da Itália e USAID (EUA), todos citados duas vezes diferentes como parceiros. A Alemanha e a Itália aparecem como os países que mais se relacionam com as organizações pesquisadas, considerando os organismos internacionais por elas destacados. No grupo "Outros parceiros", as universidades são mencionadas como parceiros por 14 organizações.

Em relação às fontes de recursos financeiros, observa-se uma grande diversidade. A maioria das organizações tem mais de uma fonte de recursos financeiros. A análise das fontes de recursos financeiros das organizações, assim como a existência de parcerias para o desenvolvimento de ações e projetos, revelam a existência de relações interorganizacionais. Outra questão que reflete neste ponto é a participação em "espaços de articulação interorganizacional", como é o caso de fóruns, conselhos (municipal, estadual ou federal), orçamento público participativo e Agenda 21 (iniciativa para discussão sobre desenvolvimento sustentável).

\section{Tabela 3 - Participação em Espaços de Articulação} Interorganizacional

\begin{tabular}{|c|c|c|c|}
\hline $\begin{array}{c}\text { Espaço de Articulação } \\
\text { Interorganizacional }\end{array}$ & Participa & $\begin{array}{l}\text { Apenas } \\
\text { conhece }\end{array}$ & $\begin{array}{c}\text { Não } \\
\text { conhece }\end{array}$ \\
\hline Conselho & $\begin{array}{c}39 \\
(21,7 \%)\end{array}$ & $27(15,0 \%)$ & $\begin{array}{c}114 \\
(63,3 \%)\end{array}$ \\
\hline Fórum & $\begin{array}{c}39 \\
(21,7 \%)\end{array}$ & $26(14,4 \%)$ & $\begin{array}{c}115 \\
(63,9 \%)\end{array}$ \\
\hline Agenda 21 & $17(9,4 \%)$ & $18(10,0 \%)$ & $\begin{array}{c}145 \\
(80,6 \%)\end{array}$ \\
\hline Orçamento Público Participativo & $3(1,7 \%)$ & $29(16,1 \%)$ & $\begin{array}{c}148 \\
(82,2 \%)\end{array}$ \\
\hline Planejamento Municipal & $15(8,3 \%)$ & $26(14,4 \%)$ & $\begin{array}{c}139 \\
(77,2 \%)\end{array}$ \\
\hline Planejamento Regional/Estadual & $9(5,0 \%)$ & $17(9,4 \%)$ & $\begin{array}{c}154 \\
(85,6 \%)\end{array}$ \\
\hline Planejamento Federal & $8(4,4 \%)$ & $15(8,3 \%)$ & $\begin{array}{c}157 \\
(87,2 \%)\end{array}$ \\
\hline Outras Iniciativas & $12(6,7 \%)$ & $6(3,3 \%)$ & $\begin{array}{c}162 \\
(90,0 \%)\end{array}$ \\
\hline
\end{tabular}

Fonte: Pesquisa direta.

Do total de organizações pesquisadas, verifica-se que:

- 97 delas (54\%) declaram não participar de nenhum dos tipos de espaços de articulação interorganizacional constantes na Tabela 3 , sendo que a maioria deste grupo não conhece nenhuma dessas iniciativas;

- 49 organizações participam de apenas um dos tipos de espaço de articulação interorganizacional constantes na Tabela 3;

- 19 organizações participam de dois dos tipos de espaço de articulação interorganizacional;

- oito organizações participam de três tipos diferentes de espaço de articulação interorganizacional. São elas: União dos Escoteiros da Bahia (UEB-BA), Associação Baiana de Recuperação do Excepcional, Grupo Ambientalista da 
Bahia (GAMBÁ), Serviços de Assessoria a Organizações Populares Rurais (SASOP), Centro de Educação e Cultura Popular (CECUP), Grupo de Recomposição Ambiental (GERMEN), Associação Campus Avançado Unipaz Bahia (Unipaz-BA) e Projeto Ibeji;

- $\quad$ cinco organizações participam de quatro tipos diferentes de espaço de articulação interorganizacional. São elas: Associação dos Funcionários Públicos do Estado da Bahia (AFPEB); Escola Nossa Senhora da Luz; Consórcio Intermunicipal do Jiquiriçá; Grêmio Recreativo e Cultural Muzenza; Associação Baiana de Adolescência (ASBA);

uma organização - Fundação Movimento OndAzul - participa de cinco tipos diferentes de espaço de articulação interorganizacional;

uma organização - Sindicato dos Jornalistas do Estado da Bahia (SINJORBA)participa de seis tipos diferentes de espaço de articulação interorganizacional.

Um percentual de $21,7 \%$ das organizações pesquisadas participa de conseIhos gestores nos âmbitos municipal, estadual e/ou federal. O mais citado, com participação de 30,7\% deste total de 39 entidades, foi o Conselho Municipal dos Direitos da Criança e do Adolescente (CMDCA). Em seguida, com quatro organizações participantes, o Conselho Municipal de Assistência Social (CMAS) e, com três citações, o Conselho Estadual dos Direitos da Criança e do Adolescente (CECA). Também foram mencionadas instâncias como o Conselho Estadual do Meio Ambiente, Conselho Estadual de Entorpecentes, Conselho Nacional de Entorpecentes (CONEN), conselhos voltados para as entidades negras e para as mulheres e Conselho Tutelar.

Ocorre também uma participação de $21,7 \%$ das organizações em fóruns diversos, espaços nos quais se articulam entidades da sociedade civil entre si e/ ou com entidades do Estado e/ou do mercado para discussão sobre problemas comuns, busca por direitos etc. É o caso, por exemplo, do Fórum de Desenvolvimento Sustentável do Centro de Salvador, em que atores das três esferas e de áreas diversas (educação, saúde, comércio, arte e cultura etc.) discutem ações para o desenvolvimento da localidade. Participam desta iniciativa seis organizações pesquisadas. Do Fórum Comunitário de Combate à Violência, articulado pela Universidade Federal da Bahia, participam cinco organizações. Do Fórum de ONGs da Associação Brasileira de ONGs (ABONG) fazem parte quatro organizações. O Fórum Estadual de Direitos Humanos e o Fórum de Defesa da Criança e do Adolescente da Bahia (FDCA/BA) foram citados, cada um, por três entidades pesquisadas. Três organizações também mencionaram o Movimento de Intercâmbio Artístico Cultural pela Cidadania (MIAC) como fórum de participação. Outros fóruns mencionados foram: Fórum de Desenvolvimento Sustentável da Península Itapagipana (Salvador), Fórum Nacional de Entidades de Defesa do Consumidor, Fórum de Educação Indígena, Fórum de Defesa do Rio São Francisco, Fórum Nacional de Defesa da Escola Pública, entre outros.

Cruzando-se a quantidade de tipos de parceiros com a quantidade de espaços de articulação interorganizacional dos quais as organizações pesquisadas participam, tem-se a seguinte matriz ${ }^{2}$ :

\footnotetext{
${ }^{2}$ No questionário cada organização indicava as parcerias e as iniciativas (1. Conselhos; 2. Fóruns; 3. Agenda 21 local; 4. Orçamentos públicos participativos; 5. Iniciativas de Desenvolvimento Local; 6. Outras). $O$ gráfico foi construido com base nas parcerias estabelecidas e as iniciativas indicadas pelas organizações. Dai foi feito um diagrama de dispersão. Este gráfico permite observar a intensidade em que a organização estabelece articulações (Iniciativas e parcerias), ou seja, auxilia na análise das organizações que conseguem fazer uma maior conexão com a rede organizacional. Desta forma, é possivel destacar a ação de organizações como Sinjorba e Onda Azul, mais conectadas, e organizações como Abrigo Mariana Magalhães, Alcóolicos Anônimos da Bahia e Associação Brasileira de Capoeira Angola, que sobrevivem sem estabelecer parcerias e iniciativas, ou seja, não indicaram no questionário como fazem parte do tecido (rede) organizacional.

Em resumo, a idéia foi tentar separar em grupos organizações com diversos perfis e depois estudar as características dos grupos buscando estabelecer padrões, na tentativa de descriminar que fatores levam a organização a estabelecer uma trama de relações mais ou menos intensa.
} 


\section{Gráfico 1 - Quantidade de Tipos de Parceiros x Quantidade de Espaços de Articulação em que se Participa}

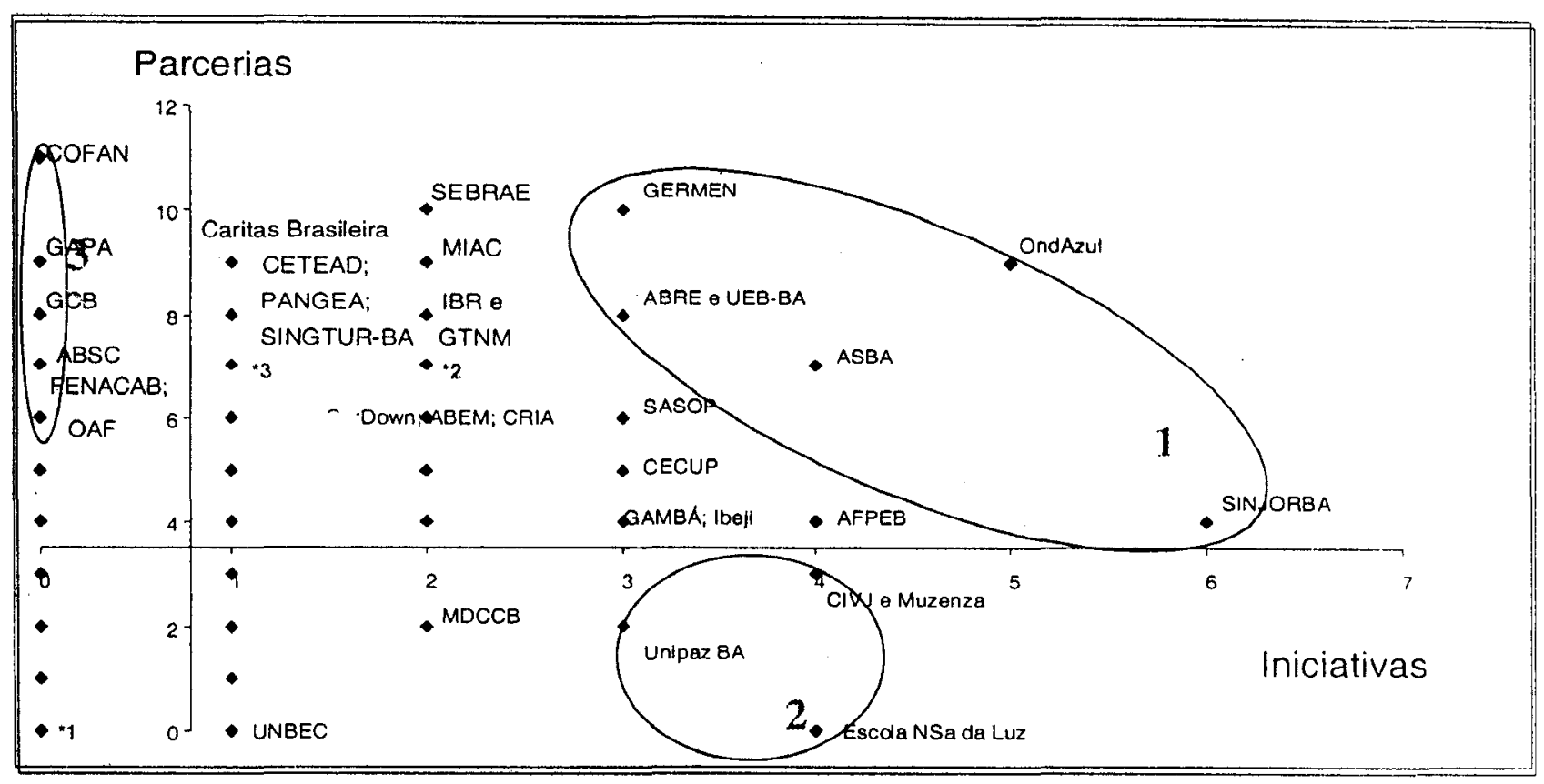

Fonte: Pesquisa direta. Elaboração de Jair Soares Jr.

O grupo 1 caracteriza-se bor uma forte articulação interorganizacional, tanto em espaços mais amplos quanto em relação a parceiros específicos. O grupo 2 participa de espaços de articulação interorganizacional em maior escala comparativamente à diversidade de parceiros que possui e o contrário ocorre com organizações do grupo 3: estas possuem diversos tipos de parceiros, mas têm baixa participação em espaços de articulação interorganizacional (espaços de discussão de políticas públicas, em sua maioria).

Procurou-se verificar se a consolidação de parcerias tem alguma relação com a existência ou não de registro no cadastro nacional de pessoa jurídica, formalização que em tese é necessária para realização de convênios e contratos e recebimento de recursos financeiros. Das 11 organizações que não possuem registro no CNPJ (nove organizações não legalizadas e dois programas/projetos): duas efetivamente não estabelecem parcerias para o desenvolvimento de projetos e ações; uma não respondeu à pergunta sobre existência de parceiros, mas recebe seus recursos financeiros exclusivamente através de doações de pessoa física, o que pode indicar a inexistência de parcerias; outras três organizações destacaram como parceiros organizações da sociedade civil (ONGs e/ou sindicatos e/ou redes/federações), mas não recebem recursos financeiros dos parceiros; e, finalmente, as cinco entidades restantes do grupo das que não possuem CNPJ tanto realizam parcerias quanto recebem recursos financeiros de instituições diversas (empresas privadas, órgãos governamentais, fundações/institutos nacionais e/ou até organismos internacionais). Para receberem recursos, certamente, articulam-se com outra organização para formalizar a documentação necessária ao repasse. Este deve ser o caso: da Escola Oficina Salvador, que atua como um projeto de extensão da UFBA; do Movimento de Intercâmbio Artístico-Cultural (MIAC), que provavelmente recebe recursos através de uma ou mais instituições que o constituem - uma vez que o MIAC é uma organização formada de organizações; do Movimento Escalada; e do Projeto Ativação.

Cabe destacar algumas figuras (inter)organizacionais observadas. Uma delas é o Movimento de Intercâmbio Artístico Cultural pela Cidadania (MIAC), que engloba organizações da área de arte-educação, funcionando segundo a lógica da ação em rede. Esta organização por si só já se caracteriza como uma interorganização enquanto espaço "de confluência e interseção de organizações" 
(Fischer, 1999). Neste caso, seria o que Pfeffer e Nowak (1976, apud Hall, 1984, p. 175) chamam de empreendimento conjunto, ou seja, "implica a criação de uma nova organização por organizações que se reúnem numa sociedade". Também se aproxima da idéia de organizações-rede (Forni, 2002).

O MIAC funciona fisicamente na sede de outra instituição também pesquisada neste trabalho, o Centro de Referência Integral de Adolescentes (CRIA), e define o seu modelo de organização conforme a figura 3.

Apesar de ter a palavra "movimento" no seu nome e de não ser legalizado juridicamente, O MIAC existe enquanto instituição desde 1997 e atua com regularidade, caracterizando-se como organização. Segundo a classificação de SchererWarren (1999), pode-se dizer que é a institucionalização de uma rede temática, aproximando-se da idéia de interface de experiências. Não pode ser caracterizado enquanto fórum de ONGs, pois é mais do que um espaço de discussão, é um espaço de ação; nem como associação de ONGs, porque não há filiação a uma associação existente e de modo formalizado.

De qualquer modo, o MIAC é exemplar do tipo de interorganização transversal, que realiza mediações de interesses.

Figura 3 - Modelo de Organização do MIAC

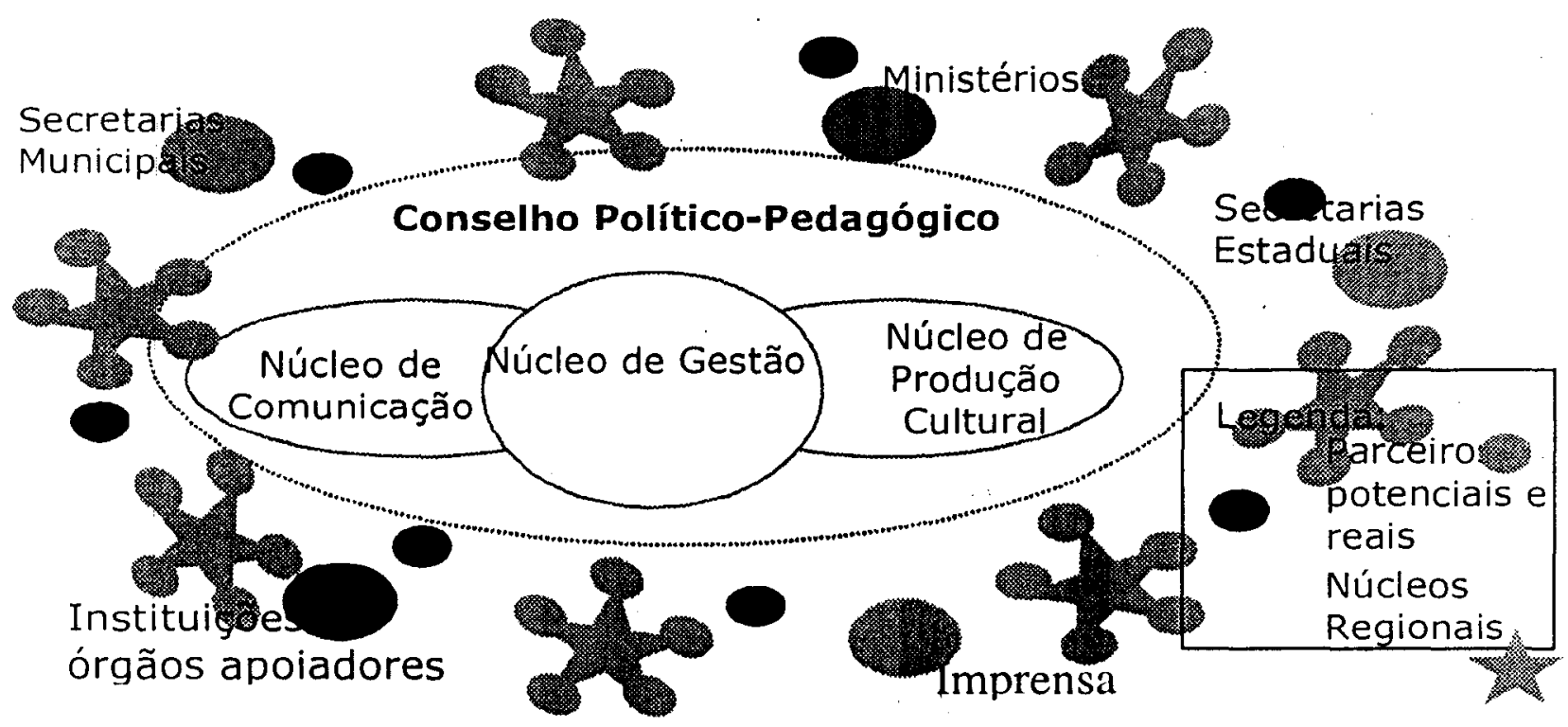

Fonte: Adaptado de www.miac.org.br (Acesso em 11/11/2002).

Neste estudo, verificou-se que o tipo de organização com a qual as organizações da sociedade civil mais estabelecem parcerias são as ONGs, as associações ou organizações comunitárias. Portanto, elas relacionam-se mais freqüentemente entre si do que com outras esferas. Interessante observar esta possibilidade se considerarmos um estudo feito por Rubem César Fernandes em 1988 (apud Santana, 1992), um dos mais importantes e pioneiros sobre entidades sem fins lucrativos no Brasil. Neste trabalho, ele ressaltou que essas organizações, em relação às demais, posicionavam-se numa situação de "evitação", cruzando-se continuamente, mas cada uma cuidando de seu negócio e evitando explicitar os interesses que a distinguiam.

Pode-se dizer que o estabelecimento ou não de parcerias tem relação com a forma com que as organizações obtêm seus recursos financeiros: todas as organizações que declararam não estabelecer parcerias obtêm esses recursos exclusi-: vamente através da fabricação/comercialização de produtos/serviços e/ou através de doações de pessoa física/contribuição de associados. 
É interessante enfatizar algumas evidências que contribuem bastante para a compreensão das interorganizações. Ao analisar as relações que cada organização mantém com outras verifica-se que, mesmo indiretamente, muitas organizações estão ligadas entre si através de parceiros comuns. Na exemplificação de formas de atuação e projetos desenvolvidos, em alguns casos, as organizações explicitaram suas relações de parceria. Assim, os projetos são importantes links de parceria. Uma análise léxica dos exemplos de projetos dados pelas organizações mostra que a palavra "parceria" está entre as mais mencionadas. Isso denota a importância da parceria para que as organizações desenvolvam ações e projetos. A palavra "rede" também é mencionada, mas em menor grau, não obstante possam ser usadas (parceria e rede) como sinônimos.

$E$, finalmente, cabe destacar que as articulações interorganizacionais referentes a ações, programas e projetos de desenvolvimento sócio-territorial constituindo-se redes de redes são ainda restritos a $1 / 5$ das ONGs estudadas.

Conselhos de políticas públicas, fóruns de desenvolvimento local e regional, como a Agenda 21, ou de planejamento em diferentes escalas contam com, aproximadamente, $20 \%$ das instituições, sendo bastante restrito o número de organizações que participam de mais de uma articulação.

Do universo pesquisado, 9,4\% participa da Agenda 21 Local, uma importante iniciativa de desenvolvimento sustentável que existe em torno de um movimento nacional. Em relação à participação em orçamentos públicos, apenas cinco organizações pesquisadas afirmam participar de iniciativa desta natureza. Tal fato é compreensível, uma vez que a Bahia não tem tradição nesta área. Nenhuma delas refere-se à capital do Estado, mas a municípios do interior onde ocorre a prática de orçamentos públicos participativos.

A que se devem estes números? A pesquisa não permite responder à pergunta, mas algumas hipóteses podem ser levantadas. Primeiro, pode haver um interesse menor das organizações por ações de maior abrangência, cujo retorno não seja visível e imediato. Segundo, há retração e escassez de ações mais abrangentes de desenvolvimento sócio-territorial em Salvador, tendo decrescido nos últimos anos as iniciativas e movimentos mais inclusivos de desenvolvimento local e metropolitano.

A participação em espaços de articulação interorganizacional, como conseIhos gestores, fóruns e Agenda 21, é indicativa de uma predisposição para a ação em rede, uma vez que as discussões devem ocorrer de forma horizontal e democrática. Por mais que na prática existam dificuldades, é importante destacar o aprendizado que as redes possibilitam, como alertam Machado e Machado (1999).

Por outro lado, em decorrência da diversidade organizacional do campo, é compreensível o fato de muitas organizações terem problemas identitários, pois ficam inclusas num universo muito amplo - que mistura organizações "quase do mercado" (como escolas particulares) e fundações e institutos de origem empresarial com organizações de base comunitária, de luta política etc. Portanto, aliado ao fato de ser um termo decorrente da negação do que seja Estado e do que seja mercado, o termo não expressa um valor identitário das organizações que o compõem, só podendo ser entendido num contexto de confrontação com os termos Estado e mercado.

A diversidade organizacional é a necessidade primordial, para grande parte das organizações, de estabelecer relações de parceria com outras organizações para concretizarem seus projetos, independentemente da motivação.

Além dos arranjos interorganizacionais mapeados na caracterização das interorganizações pesquisadas, muitos outros devem existir e permear o universo delas, considerando que a exemplificação das parcerias estabelecidas não foi diretamente solicitada aos respondentes. A partir do mapeamento das relações interorganizacionais, seria interessante um estudo mais aprofundado sobre a qualidade destas relações, a fim de verificar, por exemplo, as propriedades estruturais das redes (centralidade, tamanho, complexidade, diferenciação e conectividade). 
Apesar dessa limitação, verificou-se que a maioria das organizaçõe pesquisadas estabelece relações interorganizacionais. Esta realidade, contrarian do o pressuposto estabelecido no início da pesquisa, independe do fato de organização ser do tipo member-serving ou de interesse público e/ou coletivo. Po outro lado, o estudo apontou que o estabelecimento ou não de parcerias tem relação com a forma com que as organizações obtêm seus recursos financeiros.

Evidenciou-se, ainda, que algumas configurações organizativas encontra das no terceiro setor, por si só, já são uma contribuição no campo das interorganizações. A dificuldade de perceber algumas das organizações como per: tencentes exclusivamente à esfera do terceiro setor denota que o relacionamento interorganizacional (e inter-esferas) é marcante num campo que extrapola a esfe. ra do terceiro setor: o campo da gestão social, orientado pelo e para o social e caracterizado pela articulação interorganizacional entre sociedade civil, Estado e mercado.

Sobre as críticas feitas em relação à cooperação interorganizacional que permeia a esfera do terceiro setor e que, muitos acreditam, pode "corromper" as organizações, cabe uma ressalva: por trás desse raciocínio está a pressuposição de que as organizações do terceiro setor são todas solidárias, pautadas na racionalidade substantiva e "boazinhas" por natureza, enquanto não o são as demais organizações. Ainda que esta pressuposição fosse verdadeira, se por um lado há o risco da lógica empresarial ou estatal se sobrepor sobre a autonomia de organizações do terceiro setor em decorrência do estabelecimento de determinadas relações interorganizacionais, por outro lado é também através destas relações que a lógica das organizações do terceiro setor pode permear as organiza. ções das outras esferas. O fato é que a interação entre as organizações é uma realidade, como pôde ser constatado nesta pesquisa.

Foi possivel desmistificar alguns conceitos e preconceitos, permitindo colocar as organizações associativas num plano não idealizado para o bem - as orga. nizações "do bem" - ou para o mal. Apesar de não ter sido esse o foco do estudo, pode-se afirmar, pela análise dos perfis organizativos encontrados, que são organizações como outras quaisquer, sujeitas a contradições e críticas; e que podem ser organizações mais ou menos próximas da lógica predominante no Estado servir o interesse público - ou do mercado - servir o interesse de particulares.

\section{CONSIDERAGÓES IFINAIS}

Este estudo propiciou uma reflexão crítica sobre a gênese e a textura das interorganizações orientadas à gestão social do desenvolvimento, a partir do mapeamento das organizações associativas de caráter não governamental, percebidas como potenciais nós de redes. e tramas sócio-produtivas.

Configura-se o perfil organizativo de uma amostra do universo associativo de Salvador, questionando-se se as conexões estabelecidas no desenho interorganizacional estão referidas a ações de desenvolvimento sócio-territorial, ou, dito de outra forma, à gestão social do desenvolvimento.

Entende-se a gestão social do desenvolvimento como um processo de mediação que articula múltiplos níveis de poder, em espaços e tempos delimitados, objetivando realizações e expressando interesses coletivos de qualificação sócioterritorial. Os processo de mediação dependem da ação coordenada de atores e instituições e são transversais, na medida em que tecem as tramas sócio-produtivas que formam interorganizações.

As ONGs estudadas cumprem o papel de organizações de mediação, que procuram preservar identidade em meio a turbulência. Ao tentarem se manter e sobreviver, expandem-se em contextos de insegurança e contestação, regulando sua trajetória pelo apoio externo de entidades financiadoras (internacionais, governamentais e empresariais) e pelos marcos regulatórios em construção. Este dever permanente ocasiona mudança de posição e papéis. De parcerias do gover- 
no passam a oponentes, de braços de empresas convertem-se em entes relativamente autônomos, de movimentos sociais cristalizam-se em organizações hibridizadas entre sociedade, Estado e mercado.

Atendem, amplamente, aos critérios de totalidade, transformação e autoregulação das estruturas complexas, não obstante os evidentes dilemas entre identidade versus diversidade, sustentabilidade versus autonomia, transformação versus permanência, legitimidade versus rejeição. Contradições e ambigüidade cercam as ONGs. Críticas são feitas ao seu papel marginal às estruturas de mercado, nelas intervindo como competidoras ao gerarem produtos e serviços ou às funções que exercem na gestão de políticas públicas, no momento em que há uma recentralização dos poderes de Estado no âmbito federal.

Sendo institucionalizadas, as ONGs têm autonomia relativa, mas controle social precário. Não sendo lucrativas, devem ser sustentáveis e hoje se constituem em espaços de trabalho disputados por acadêmicos e gestores sociais. Talvez a dimensão mais contraditória e fascinante das ONGs seja o seu caráter de experimento social e organizacional, como incubadoras de práticas e matriz de novos desenhos institucionais.

Ao serem parte da sociedade que interpelam e combatem, são "marginais comprometidos", reificando o papel que ocupam nos vácuos institucionais, nas margens e nos intersticios interorganizacionais.

Organização que se afirma pela negação - não governamental, não empresarial - as ONGs são tão mais contraditórias quanto mais se integram a outras organizações constituindo interorganizações.

Por iniciativa do governo federal, estadual, de agências de desenvolvimento, de movimentos sociais e redes de organizações associativas, os arranjos produtivos, bem como os empreendimentos de caráter solidário, requerem participação social mais ampla na forma de redes de redes (consórcios, conselhos, fóruns, pactos).

A maior articulação interorganizacional dependerá, também, das políticas de desenvolvimento local visando à requalificação urbano-regional, traduzida em planos estratégicos.

Concluindo, o estudo de organizações e interorganizações de natureza associativa em Salvador tem as limitações de uma pesquisa de tipo survey, ou seja, é um estudo configuracional que descreve uma amostra e aponta pistas para futuros estudos, tais como: a) análise de clusters organizativos, com amostras setoriais (saúde, gênero, ambiente, cultura, infância e adolescência, etnicidade) em Salvador, com especial destaque às transformações verificadas nas organizações não governamentais relacionadas à cultura e ao turismo (sobretudo as afroculturais) em função das políticas federais, estaduais e municipais, b) mapeamento de ONGs no interior do Estado e comparações entre a capital e o interior; c) estudos de avaliação sobre tramas sócio-produtivas como arranjos e empreendimentos de caráter solidário quanto à estrutura e estratégias de desenvolvimento; d) estudos sobre natureza das relações de cooperação e conflito e o papel dos atores nestes processos; e) estudos sobre as influências culturais exercidas por agentes financiadores internacionais na lógica organizacional e interorganizacionais; f) estudos de caso sobre instituições gestoras de políticas, programas e projetos de desenvolvimento sócio-territorial e suas relações com as organizações não governamentais: g) estudos sobre perfis de gestores de organizações e interorganizações.

As organizações, redes de redes que apresentam um perfil mais integrador merecem estudos qualitativos que permitam perceber as especificidades e nuances de tais organizações (ou interorganizações). História das organizações e história de vida dos seus líderes podem ser utilizadas para explicar trajetórias de sucesso e insucesso na gestão territorial.

É de se supor que políticas de apoio ao desenvolvimento local e regional devam considerar as organizações e interorganizações identificadas como representativas do tecido associativo, com legitimidade na representação dos interesses da sociedade. 
Retorna-se, ao final deste texto, ao compromisso assumindo pelo grupo de pesquisa no início dos anos 90 de estudar poderes territorialmente localizados, analisando territórios pelo menos em três dimensões: como espaços políticos e simbólicos, como espaços de produção e consumo de bens, serviços e significados e como espaços de organização e gestão.

$\mathrm{Na}$ "análise do local", estruturas cada vez mais complexas requerem transversalidade e trato interdisciplinar e as estratégias de desenvolvimento um diálogo mais produtivo entre acadêmicos e gestores, reduzindo distâncias entre realidades e utopias.

\section{$\mathbb{R} \mathbb{E} \mathbb{E} \mathbb{R} \hat{\mathbb{E} N \mathbb{N} \mathbb{A} S}$}

ALTER, Catharine; HAGE, Jerald. Organizations working together. Newbury Park:SAGE, 1993.

ANDRADE, José Célio et al. Restrição-Prima para o Artesanato Local na Àrea de Influência do Projeto Costa do Suípe: caso para ensino. IX Colóquio Internacional sobre Poder Local, Salvador, Bahia, 2003. Cd Rom

AVENIER, M.J. La stratégie chemin faisant. Paris: Economica, 1997.

BABBIE, Earl. Métodos de pesquisas de survey. Belo Horizonte: UFMG, 1999.

ALVES, Mário Aquino. Terceiro Setor. O Dialogismo Polêmico. 2002. Tese (Doutorado em Administração) - FGV/EAESO, Fundação Getúlio Vargas.

BOUCHIKHI, H. Structiration des organisations. Paris: Economica, 1990.

BOURDON, R. A quoi sert la notion de structure? Paris: Gallimard, 1968.

BURNS, T. e STALKER, G. The Management of innovation. Londres, Tavistoch, 1961 BURREL, G e MORGAN, G. Sociological paradigms and organizational analysis, Londres, Heineman Books, 1989.

CARVALHO, Cristina Amélia Pereira. A transformação das ONGs no Brasil: um processo de isomorfismo com as ONGs do Norte. In: Encontro Nacional de Estudos Organizacionais (ENEO). I, 2000, Recife. Anais... Recife: Observatório da Realidade Organizacional, PROPAD/UFPE, ANPAD.

CARVALHO-FERREIRA, J. Les potentialitès de developement du troisiene secteur dans les societès contemporaines. Comunicação apresentada no AISLF. Tours, França, 2004.

CARTA DE PRINCÍPIOS. Associação Brasileira de Organizações Não-Governamentais. Disponível em: < www.abong.org.br $>$. Acesso em: 10/08/2004

CASTRO, Rocío C. Genero-etnia-classe: reflexión sobre la genealogía del poder a partir del estudio de las mujeres negras en Salvador. In: SIMPOSIO GÉNERO EN LA REGIÓN SUBANDINA. Cochabamba, 1998.

CLARK, P. Organisations in action. Londres: Rouletge, 2000.

COSSETE, P. L'organisation. Una perspective cognitiviste. Quebec: Les Presses de I'Université Laval, 2004.

DANTAS, Marcelo. Olodum: de bloco afro a holding cultural. Salvador: Olodum/ Fundação Casa de Jorge Amado, 1994, 132 p.

; FISCHER, Tânia. Brazil's Olodum - Mobilizing social development trough music. The International Executive. New York, 1994.

DEGĖNNE, A. e TORSĖ, M. Les réseaux sociaux. Paris: Armand Collin, 2004.

DESMERAUX, A. Theorie des organisations. Paris: Editions SEM, 1998. 
ERALY, A. La structuration de l'enterprise. La rationalitè en action. Bruxelas: Editions de L'Université de Bruxelas, 1988.

ETZIONI, A. The essencial communitarian reader. Nova York: Prentice Hall, 1998.

Complex Organizations. Nova York: Rouletge, 1961

FADUL, Élvia. Novos temas ou reatualização de velhas questões: a articulação público/privado nos serviços de limpeza urbana. In: FISCHER, Tânia. (Org.). Poder local: governo e cidadania. Rio de Janeiro: FGV, 1993.

Orçamento participativo: limites e contradições de um modelo decisório inovador. In: IVO, Anete Brito Leal (Org.). O poder da cidade: os limites da governança urbana em Salvador. Salvador, 2000, p.121-149.

FAYOL, H. Administration industrielle et genérale. Paris: DUNOD, 1988.

FERNANDES, Rubem César. Privado porém Público. O Terceiro Setor na América Latina. Rio de Janeiro: Relume-Dumará, 1994.

FERRAZ, Aparecida; FISCHER, Tânia. Liderança e mediação de identidade: a palavra dos líderes e a voz da mídia. IN: XXV ENCONTRO NACIONAL DA ASSOCIAÇÃO NACIONAL DE PÓS-GRADUAÇÃO EM ADMINISTRAÇÃO (ENANPAD). Anais... CAMPINAS, 2001. CD ROM.

FISCHER, Rosa Maria; FALCONER, Andrés Pablo. Desafios da Parceria GovernoTerceiro Setor. Rio de Janeiro: I Encontro da Rede de Pesquisas sobre o Terceiro Setor na América Latina e Caribe - ISTR, 1998. Disponivel em <http:// www.rits.org.br> Acesso em 7 Abr.

FISCHER, Tânia (Org.). Gestão contemporânea: cidades estratégicas e organizações locais. Rio de Janeiro: FGV, 1996. 207 p.

. (Org:) Gestão do desenvolvimento e poderes locais: marcos teóricos e avaliação. Salvador: Casa da Qualidade, 2002.

. Gestão contemporânea, cidades estratégicas: aprendendo com fragmentos e reconfigurações do local. In: FISCHER, Tânia(Org.). Gestão contemporânea: cidades estratégicas e organizações locais. Rio de Janeiro: FGV, 1996, 207 p.

Interorganizações e Instituições como Recursos ao Desenvolvimento Local. Projeto de Pesquisa apresentado ao CNPq. Salvador: Escola de Administração da UFBA, NEPOL, 1999.

; DANTAS, Marcelo. Groupe culturel Olodum - la stratégie des acteurs. In: 2ĖmE CONFERÉNCE SUR LE MANAGEMENT DES ARTS ET LA CULTURE. Anais... França, v. 2, 1993.

; HEBER, Florence; FADUL, Élvia.; FACHIN, Roberto. Capacitación avanzada en regulación: desafíos institucinales a las interorganizaciones del sector de energía elétrica en Brasil y alternativas críticas a la retórica de la competencia. In: XXXVI ASEMBLEA DEL CONSEJO LATINOAMERICANO DE ESCUELAS DE ADMINISTRACIÓN. Anais... México, 2001, CD ROM.

; MAC-ALLISTER, Mônica, et al. A cidade como tela organizacional: inovações, continuidades e ressonâncias culturais - Salvador da Bahia, cidade puzzle. In: MOTTA, Fernando C. Prestes; CALDAS, Miguel (Org.). Cultura organizacional e cultura brasileira. São Paulo: Atlas, 1997.

; MELO, Vanessa P. Gestão social do desenvolvimento e interorganizações. In: IX COLÓQUIO INTERNACIONAL SOBRE PODER LOCAL. Anais... Salvador, v.1, 2003.

; TEIXEIRA, Ângela. Réseaux sociaux, citoyenneté et gestion publique à Salvador, Bahia. In: 2 ėme CONFERENCE EUROPÉENNE SUR L'ANALYSE DES RÉSEAUX SOCIAUX. Résumés des Communications: Abstracts. Paris, 1991, p. 68-69. 
; TEIXEIRA, Angela; CARVALHO, Juvenilda; MOURA, Maria Suzana. Redes sociais e associacionismo: um estudo em três bairros de Salvador. XVII ENCONTRO NACIONAL DA ASSOCIAÇÃO NACIONAL DE PÓS-GRADUAÇÃO EM ADMINISTRAÇÃO (ENANPAD). Anais ... Salvador, 1993.

; GINBO, Yeda. The carnival of Bahia as an organizational web and competitive project. In: XVI SCOS- STANDING CONFERENCE ON ORGANIZATIONAL SYMBOLISM. Abstracts... July 2-6, 1998.

FOLLET, M. P. Dynamic administration. The collected papers of Mary Parker Follet. Londres: Pitman, 1973.

FORNI, Pablo. Las Redes Inter-organizacionales y sus implicaciones en el desarrollo de las Organizaciones Comunitarias de los Pobres y Excluidos: estudios de caso em el Gran Buenos Aires durante la década del noventa. In: Encontro de Estudos Organizacionais (ENEO), II, 2002, Recife. Anais... Recife: Observatório da Realidade Organizacional, PROPAD/UFPE, ANPAD.

FRANÇA FILHO, Genauto C. A problemática da economia solidária: um novo modo de gestão pública? In:XXVI ENANPAD - ENCONTRO NACIONAL DA ASSOCIAÇÃO NACIONAL DE PROGRAMAS DE PÓS-GRADUAÇÃO EM ADMINISTRAÇÃO. Anais... Salvador, 2002.

. A Gestão Social: um conceito em construção. In: IX COLÓQUIO INTERNACIONAL SOBRE PODER LOCAL. Anais... Salvador, 2003.

; DZIMIRA. Sylvain Don et économie solidaire. Paris: CRIDA/ GERFA/ MAUSS, 2000. (Collection La Petit Bibliothéque du MAUSS).

; LAVILLE, Jean Louis. A Economia Solidária numa perspectiva internacional. Vozes: Petrópolis, 2003. (no prelo).

FROEHLICHER,T.; WALLISER. B. La mètamorphose des organisations - Design organisationnel: crèer, innover, relier. Paris: Puf, 2003.

GAIGER, L. Sentidos e experiência de economia solidária no Brasil. Porto Alegre. Editora UFRGS,2004.

GAUDIN, J. P. Development local et action publique, Paris, Economia, 2003.

GUIMARÃES, N.; MARTIN, S. Competitividade e desenvolvimento. Atores e instituições locais. São Paulo: Biblioteca SENAC, 2001.

GOHN, Maria da Glória. Movimentos Sociais e ONG's no Brasil na Era da Globalização. In: . Teoria dos Movimentos Sociais. Paradigmas clássicos e contemporâneos. São Paulo: Edições Loyola, 1997

HALL, Richard H. Organizações: estrutura e processos. Rio de Janeiro: PrenticeHall do Brasil, 1984.

HEBER, Florence. et al. De Pelourinho a Shopping Cultural. In: FACHIN, R. Governo Municipal na América Latina. Porto Alegre, Sulina, 1998.

; MOURA, Maria Suzana.; FISCHER, Tânia. Centro Histórico de Salvador: shopping cultural a céu aberto? In: FACHIN, R.; CHANLAT, A. Municipios na América Latina: inovações e novas perplexidades. Porto Alegre: Sulina, 1998.

KILDUFF, Martin. e TSAI, N. social networks and organizations. Londres: Sage, 2003.

e TSAI, Nenpin. Social networks and organizations. Londres, SAGE Publications, 2003, 172p.

LANIADO, Ruthy N., BAIARDI, Amilcar. Networks, associativism and regional culture In A Globalized Society In: XV INTERNATIONAL CONGRESS OF SOCIOLOGY. Anais... Brisbane, 2002. 
LASTRES, H; CASSIOLATO, J.E. O enfoque em sistemas produtivos e inovações locais. In. FISCHER, T. (org) Gestão do Desenvolvimento e Poderes Locais. Salvador: Casa da Qualidade, 2002.

LAVILLE, J. L. L'économic solidaire. Une perspective internationale. Paris: Deselée de Brouwer, 2000.

LAWRENCE, P. e LORSCH, J.W. Organization and environmment: managing differentiation and integration. Cambrigde, 1967.

LEMIEUX, Vincent. Les rèseaux d'acteurs sociaux. Paris: Puf, 1999.

LONG, J. Scott. Regression models for categorical and limited dependent variables. Thousand Oaks: Sage Publications, 1997.

MAC-ALLISTER, Mônica. A cidade no campo dos estudos organizacionais. In: IX COLÓQUIO INTERNACIONAL SOBRE PODER LOCAL. Anais... Salvador, v.1, 2003.

MACHADO, Antonio L. Itriago; MACHADO, Miguel Angelo Itriago. Las redes como instrumentos de transformación social. RITS, Caracas, 1999. Seção Acervo. Disponível em: <http://www.rits.org.br>. Acesso em 04 jul. 2000.

MACHADO-DA-SILVA, C. e COSER, C. Argumentos estruturais para explicação do isomorfismo mimétrico em um campo organizacional. Anais do ENEO. Cd Rorn. 2004 MARTINET, A.; THIETHART, R. Stratégies. Actualités et future de la recherche. Paris: Vuibert, 2001.

MEDINA, Miriam. Participação e Espaço Urbano no Contexto Colombiano. 1997. Dissertação (Mestrado em Arquitetura e Urbanismo) - Faculdade de Arquitetura e Urbanismo, Universidade de São Paulo, São Paulo, 1997.

MEISTER, A. Vers une sociologie des associations. Paris Economie et Humanisme. Ed. Ouvrière, 1992.

MIGUEZ, Paulo; LOIOLA, Elizabete. Lúdicos mistérios da economia do carnaval baiano: trama de redes e inovações. IN: XIX ENCONTRO NACIONAL DA ASSOCIAÇÃO NACIONAL DE PÓS-GRADUAÇÃO EM ADMINISTRAÇÃO (ENANPAD). Anais... João Pessoa, 1995.

MILANI, Carlos Roberto S., ARTURI, Carlos, SOLINÍS, Germán. (org.) Democracia e Governança Mundial. Porto Alegre : UFRGS/UNESCO, 2002 p.295.

; SOLINÍS, Gernán; LEAL, Suely; NUNES, Débora; BIÉ, Maury D.; RIBEIRO, Julia Taís; SACERDOTE, Austílio T. N. As dimensões políticas do desenvolvimento local: o capital social e as relações entre a sociedade civil e o poder público. In: IX COLÓQUIO INTERNACIONAL SOBRE PODER LOCAL. Caderno de resumos... Salvador, V.1, 2003.

MINTZBERG, H. Structure et dynamique desorganisations. Paris: Editons d'Organizations, 1969.

MOURA, Maria Suzana. Cidade estratégica e gestão empreendedora: uma operação de planejamento, pacto e marketing. In: XX ENCONTRO NACIONAL DA ASSOCIAÇÃO NACIONAL DE PÓS-GRADUAÇÃO EM ADMINISTRAÇÃO (ENANPAD). Anais... Angra dos Reis, 1996.

. Cidades Empreendedoras, Cidades Democráticas e Redes Públicas: Tendências à Renovação na Gestão Local. 1997. Tese (Doutorado em Administração) - Escola de Administração, Universidade Federal da Bahia, Salvador, 1997.

; CASTRO, Rocío; MELO, Vanessa P.; LORDELLO, José Albertino; MEIRA, Ludmila. Desenvolvimento local e sustentável: o que sinalizam as práticas. In: XXVI ENCONTRO NACIONAL DOS PROGRAMAS DE PÓS-GRADUAÇÃO EM ADMINISTRAÇÃO. Anais... Salvador, 2002. 
et al. Desenvolvimento local sustentável o que sinalizam as práticas. In: Congresso da Associação Latino-Americana de Sociologia (ALAS), XXVII, 2001. Ciaudad de Guatemala. Anais... Guatemala: ALAS.

MUSSO, Pierre. Rèseaux et sociètè. Paris: Puf, 2003.

. Critique des Rèseaux. Paris: Puf, 2003.

PATIRI, Vitor. Projetos Ecológicos e o Desenvolvimento Local: um estudo de caso do Projeto TAMAR. Dissertação. Escola de Administração, NPGA/UFBA, Salvador, Ba. 2002.

PARROCHIE. La philosofie des reseaux. Paris PUF, 1996.

PIAGET, Jean. O estruturalismo. Nobel: São Paulo, 1968.

PINHO, José Antonio G. de; AKUTSU, Luiz. Governo eletrônico, sociedade civil e democracia: revisitando portais de governo no Brasil. In: IX COLÓQUIO INTERNACIONAL SOBRE PODER LOCAL. Anais... Salvador, v.1, 2003.

Inovação na gestão municipal no Brasil: a voz dos gestores municipais? In: IX COLÓQUIO INTERNACIONAL SOBRE PODER LOCAL. Anais... Salvador, v. 1, 2003.

Serviço de Atendimento ao Cidadão - SAC. In: VII COLÓQUIO INTERNACIONAL SOBRE PODER LOCAL. Anais... Salvador, 1997.

; SANTANA, Mercejane Wanderley. Inovação na gestão pública no Brasil: uma aproximação teórico-conceitual. In: ENCONTRO NACIONAL DA ASSOCIAÇÃO NACIONAL DE PÓS-GRADUAÇÃO EM ADMINISTRAÇÃO (ENANPAD). Anais...Foz do Iguaçu, 1998. CD ROM.

SANTANA Mercejane Wanderley; CERQUEIRA, Sonia. Gestão pública em busca da cidadania: experiências de inovação em Salvador. In: VII COLÓQUIO INTERNACIONAL SOBRE PODER LOCAL. Anais... Salvador, 1997.

PUTNAN, R.; LEORNADI, R., NANETTI, R. Making democracy work. Princepton: Princepton University Press, 1993

ROSSI, P. A estrutura de organização de uma comunidade americana. In: ETZIONI, A. Organizações Complexas. São Paulo: Atlas, 1973.

SAINSAUliEU, R. Des societés en mouvement. Paris: Desclée de Brouwer, 2001.

SAMPAIO, Heliodoro. Cidade real, cidade e ideal. Salvador: EdUFBA, 1999.

SANTANA, Maria das Graças Firpo Sandes. Organizações não-governamentais no Brasil: um estudo de caso. 1992. Dissertação (Mestrado em Administração) - Escola de Administração, Universidade Federal da Bahia, Salvador, 1992.

SANTOS, M. A natureza do espaço. São Paulo: Hucitec, 1999.

ONGs latino-americanas. Construindo redes cidadã́s. In: Cidadania sem Fronteiras: Ações Coletivas na Era da Globalização. São Paulo: Hucitec, 1999.

SANTOS, Maria Elisabete Pereira et al. Política Pública e Gestão Urbano-Ambiental. Comunicação apresentada no IX Colóquio Internacional sobre Poder Local, Salvador, Bahia, 2003. Caderno de Resumos.

SCHOMMER, Paula. Investimento social das empresas: cooperação organizacional num espaço compartilhado. In: XXIX ENCONTRO NACIONAL DA ASSOCIAÇÃO NACIONAL DE PÓS-GRADUAÇÃO EM ADMINISTRAÇÃO (ENANPAD). Anais... Florianópolis, 2000. CD ROM.

SCOTT, W. e CHISTENSEN, S. The institucional construction of organizations. International and longitudinal Studies. Londres: SAGE, 1995.

SCOTT, J. Networks of corporate power. New York. The Pree Press, 2000 
SEBRAE. Territórios de baixo densidade empresarial. Brasília, SEBRAE, 2003.

SCHERER-WARREN, IIse. ONGs Latino-americanas Construindo Redes Cidadãs. In: Cidadania sem Fronteiras: Ações Coletivas na Era da Globalização. São Paulo: Hucitec, 1999.

SIQUEIRA, Maria de Lourdes. As dimensões organizativas da cultura afro-baiana. In: FISCHER, Tânia (Org.). Poder local: governo e cidadania. Rio de Janeiro: FGV, 1993, p. 164-176.

SORJ, B. A democracia inspirada. Rio de Janeiro: Jorge Zahar Editores, 2004.

STRATI, A.. Organization studies. theory and method. Londres. SAGE, 2000.

SUPERITENDÊNCIA DE ESTUDOS ECONÔMICOS E SOCIAIS DA BAHIA. Empreendimentos solidários do RMS de Salvador e Litoral Norte da Bahia. Salvador, SEI, 2004.

TEODÓSIO, Armindo dos Santos de Sousa. Pensar o terceiro setor pelo avesso: dilemas e perspectivas da ação social organizada na gestão pública. In: Encontro da Associação Nacional de Programas de Pós-graduação em Administração (ENANPAD), XXV, 2001, Campinas. Anais... Campinas: ANPAD.

VIEIRA, E; VIEIRA, M. Geoestratégia dos espaços econômicos. Poder local e poder global na gestão do território

VILLASSANTE, T. Las ciudades hablan. Caracas. Editora Nueva Sociedad, 1998.

WEICK, K.. Making sense of the organization. Nova York: Blackwell, 2001.

WOODWARD, J. Magament et techonology. In Burns, T. Industrial man. Londres, Norvich, 1968. 